\title{
AN OVERVIEW OF INNOVATIVE STRATEGIES FOR FRACTURE MECHANICS AT NASA LANGLEY RESEARCH CENTER
}

\author{
J.B. Ransom ${ }^{1}$, E. H. Glaessgen ${ }^{2}$, and J. G. Ratcliffe ${ }^{3}$ \\ Durability, Damage Tolerance and Reliability Branch \\ NASA Langley Research Center, Hampton, Virginia, 23681, U.S.A.
}

\begin{abstract}
Engineering fracture mechanics has played a vital role in the development and certification of virtually every aerospace vehicle that has been developed since the mid-20 ${ }^{\text {th }}$ century. NASA Langley Research Center's Durability, Damage Tolerance and Reliability Branch has contributed to the development and implementation of many fracture mechanics methods aimed at predicting and characterizing damage in both metallic and composite materials. This paper presents a selection of computational, analytical and experimental strategies that have been developed by the branch for assessing damage growth under monotonic and cyclic loading and for characterizing the damage tolerance of aerospace structures.
\end{abstract}

\section{Introduction}

Engineering fracture mechanics, in particular linear elastic fracture mechanics (LEFM), has played a vital role in the development and certification of virtually every aerospace vehicle that has been developed since the mid- $20^{\text {th }}$ century. Often, LEFM is associated with a damage tolerance design philosophy where a critical flaw size must be significantly larger than the minimum detectable flaw (e.g., crack) to insure safety. Here, the critical flaw is assumed to exist in a location and under a loading where fracture occurs. In this philosophy, analysis or testing, or a combination of both must show that the detectable crack will not reach a critical length before a subsequent inspection.

Traditional engineering fracture mechanics is a continuum mechanics construct that is based on the premise that crack growth will occur when a computed fracture parameter reaches its empirically determined critical value. For example, brittle fracture in metals (in plane strain) will occur when $K_{I}>K_{I C}$, i.e. when the computed value of the stress intensity factor, $K_{I}$, is greater than or equal to the experimentally obtained fracture toughness, $K_{I C}$. In engineering fracture mechanics, fracture toughness is considered to be a property of the material, and the plane strain fracture toughness, $K_{I C}$, is the lowest value of material toughness. Similarly in laminated composite materials that are susceptible to failure mechanisms such as delamination, the strain energy release rate, $G$, has been traditionally used as a measure of the driving force for delamination growth. In a manner similar to that employed for brittle fracture in metals, onset of delamination growth is expected to take place when $G$ becomes equal to or greater than a critical value $G_{c}$. As a consequence of delamination growth being constrained by the bounding plies, a mixed mode loading condition can be imparted along the delamination front, involving opening and shear components of $G$. In such cases, the total strain energy release rate must be

\footnotetext{
${ }^{1}$ Branch Head, Durability, Damage Tolerance and Reliability Branch. Member AIAA

${ }^{2}$ Assistant Branch Head, Durability, Damage Tolerance and Reliability Branch. Associate Fellow AIAA

${ }^{3}$ Senior Materials Research Engineer, National Institute of Aerospace, Resident at the Durability, Damage Tolerance and Reliability Branch.
} 
decomposed into its individual components, and a mixed-mode delamination growth criterion must be used to determine the onset of growth.

There are numerous examples of fracture-related mechanisms exhibited by both metallic and composite structure where LEFM fails to provide a sufficient representation of the failure mechanism in question. Examples include fracture in metals involving significant levels of metal plasticity and delamination growth in composite laminates that is accompanied by additional energy dissipating mechanisms such as fiber bridging or the failure of through-the-thickness reinforcement. In these circumstances, approaches are required that either involve alternative approaches to LEFM or employ LEFM-based approaches that are amended to account for the additional failure mechanisms.

Furthermore, with the increasing use of composite materials in airframe primary structure, there is motivation to improve the efficiency of the certification of these relatively new materials. The typical response to this situation has been the attempt to establish damage tolerance analysis methods for replacing, and thus reducing, the amount of testing involved in certifying a composite structure.

Consequently, the Durability, Damage Tolerance and Reliability Branch (DDTRB) at NASA Langley Research Center (LaRC) continues to develop a broad portfolio of fracture mechanics methods aimed at understanding damage in both metallic and composite aerospace structures. Additionally, the branch continues to develop methods with the aim of decreasing the time required for certifying aerospace structures. The latter aim has motivated the development of analysis methods for new forms of metallic structure and has lead to a continued effort that is geared towards the development of standardized testing practices for characterizing various fracture mechanisms in composite materials.

This paper presents an overview of the computational, analytical and experimental strategies for fracture mechanics for fatigue, fracture and damage tolerance of metallic and composite aerospace structures at NASA Langley Research Center (LaRC). Methodologies for simulating and characterizing fatigue and fracture of metallic materials are presented. This discussion includes new methodologies in continuum mechanics as well a new paradigm in damage mechanics, referred to herein as damage science. Damage tolerance capabilities for composite structures, including sandwich construction are then presented. A selection of activities associated with composite materials is presented, including those involved with the development of test standards, prediction and verification methods for delamination and debonding of composite laminates and the identification of failure mechanisms for a recent failure investigation.

\section{Fracture Mechanics of Metallic Materials}

Although methodologies for characterization of the fatigue and fracture of metallic materials have been extensively developed over the past several decades, work in this area remains an active topic of research. The focus of much of the work in the branch in metallic materials has centered on development of methods to predict crack growth in 
new material forms (e.g., friction stir weld panels) and to improve our understanding of the fundamental mechanisms of deformation and fracture. The effort on predicting crack growth in new material forms builds upon well-established methods in continuum fracture mechanics for predicting fracture in built-up structures. Conversely, a relatively new and largely unproven effort has also been undertaken that offers the promise of changing the fundamental paradigm of fracture mechanics (and greatly extending the length scales for which it is valid) by examining damage processes at the micro- and even the nano-scale. This section will discuss work in the broad range from continuum fracture mechanics to atomistic simulation of fundamental damage processes.

\section{Residual Strength Predictions for Friction Stir Weld Panels}

Friction stir welding (FSW) is a new solid state joining technology that is being considered by many airframe manufacturers as a replacement for traditional joining methods. As is common with other welding methods, FSW results in a residual stress state that may affect crack growth rates. Thus, determination of the fatigue life of friction-stir-welded structure requires the ability to predict the residual stress intensity, $\mathrm{K}_{\text {residual. }}$.

A new method being developed to predict $\mathrm{K}_{\text {residual }}$ is based on determination of equivalent thermal loads ${ }^{1}$. Equivalent thermal loads are calculated by defining initial strain due to welding along the length and width of the weld region. The method determines the equivalent thermal loads that produce the residual stress field using the elastic modulus, $\mathrm{E}$, coefficient of thermal expansion, $\alpha$, and change in temperature, $\Delta \mathrm{T}$. The methodology always satisfies self-equilibrium and allows rapid convergence. Temperature change, $\Delta \mathrm{T}$, is calibrated by comparing the predicted residual stress field to that measured for coupon test data. Similitude can be assumed such that the same $\Delta \mathrm{T}$ may be used to generate residual stress fields for any other configuration (specimen type, component or panel of any size and shape) as long as the same welding parameters are used.

The analysis results are compared with experimental data obtained from both cutcompliance and crack-compliance tests. Compact tension $\mathrm{C}(\mathrm{T})$ specimens that are 4 inches wide and 0.25 inches thick representing two welding configurations (tensiledominated and compression-dominated) were modeled using isoparametric eight-node brick elements in the ZIP3D finite element code as shown in Figure 1 (half the specimens were modeled on the assumption of symmetry about the x-axis). Aluminum alloy 2024T3 was considered for all analyses with modulus, $\mathrm{E}=10 \mathrm{Msi}$, and coefficient of thermal expansion, $\alpha=13.0 \times 10^{-6}$ in $/$ in $^{\circ} \mathrm{F}$. By comparing the predicted residual stress intensity factor (SIF) distribution to the experimentally measured values in the weld zone, the change in temperature was empirically determined to be $-200^{\circ} \mathrm{F}$ for the tensile-dominated configuration. This same value of $\Delta \mathrm{T}$ was then applied to the finite element analysis of the compression-dominated specimen. Stress intensity factor solutions were generated using virtual crack closure technique (VCCT) and the J-integral technique and are shown in Figures 2 and 3. Both crack-compliance (symbols) and cut-compliance (lines) experimental data are shown for comparison. The SIF solution compares well with experimental data. 

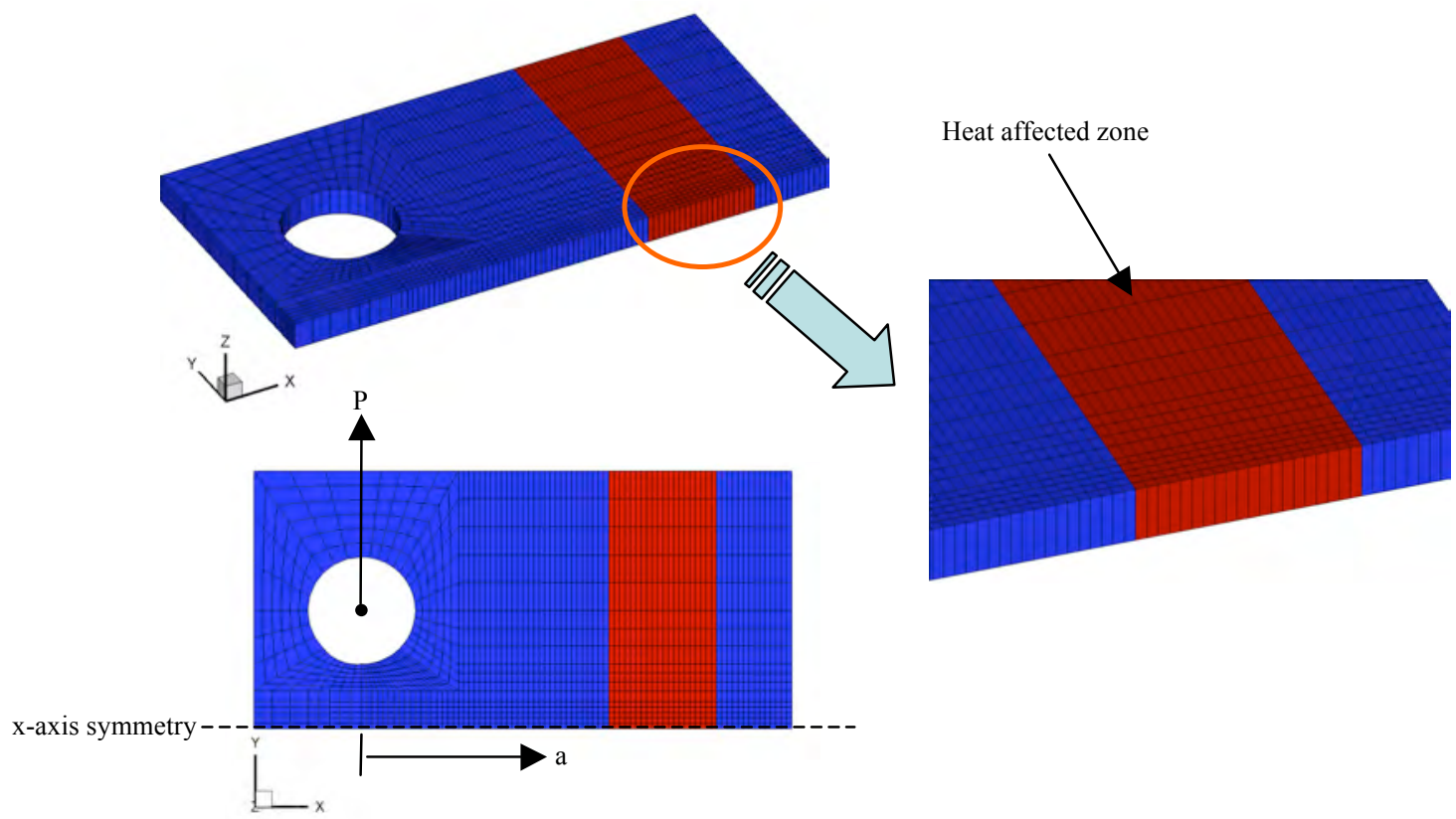

Figure 1: A typical finite element mesh for 4-inch wide $\mathrm{C}(\mathrm{T})$ specimen

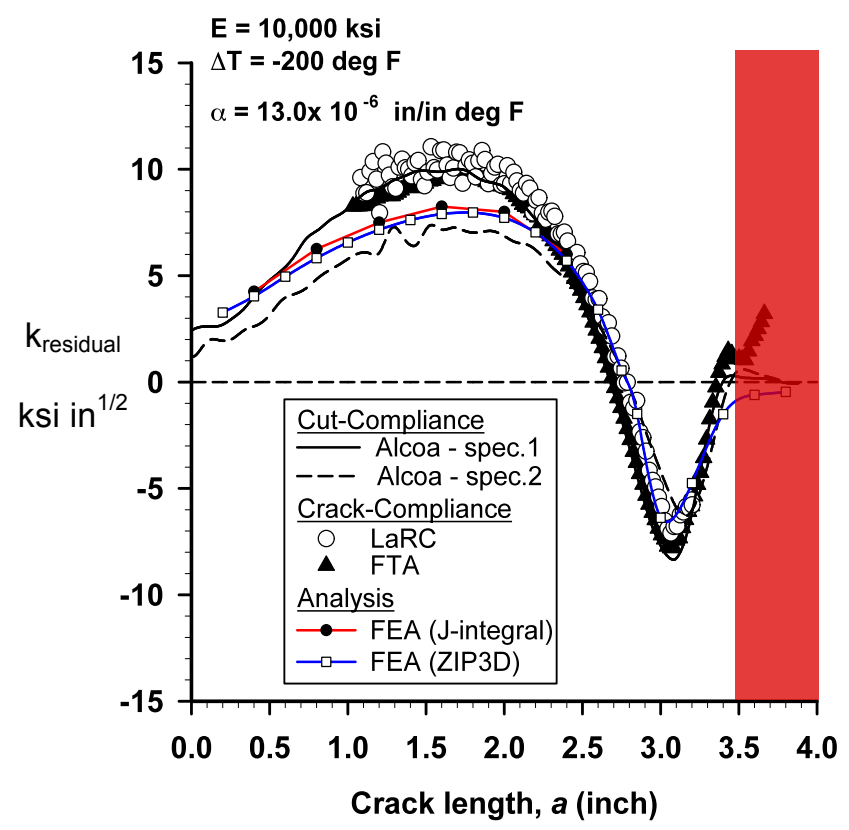

Figure 2: Residual stress varıation tor tension-domınated specimen. Experimental data are shown for comparison 


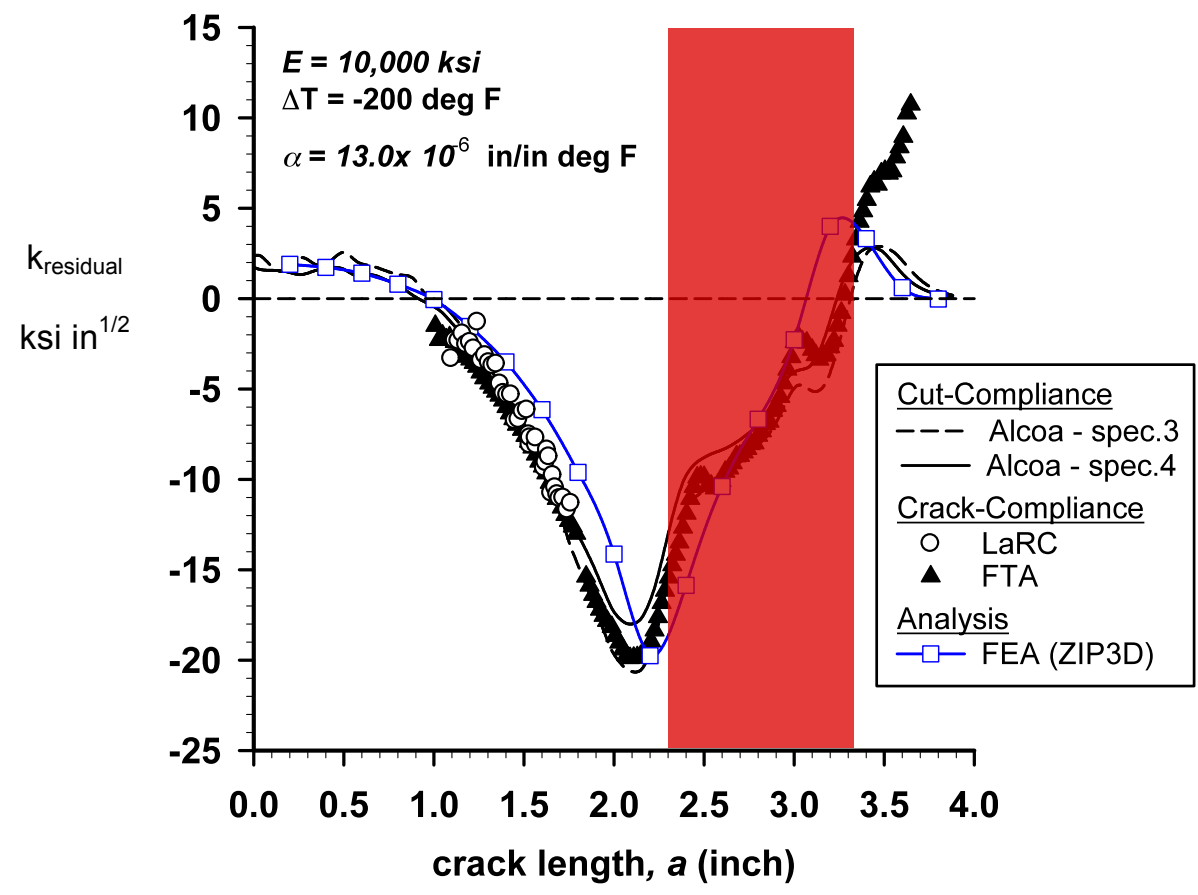

Figure 3: Residual stress variation for compression-dominated specimen. Experimental data are shown for comparison

Once the residual stress distributions were determined, their effects on residual strength could be determined. Because the 4-inch wide $\mathrm{C}(\mathrm{T})$ specimen was manufactured using procedures that mimicked those used on production panels, similitude between the coupon tests and complex FSW panels could be assumed. Hence, the thermal parameters obtained from the analyses of the $\mathrm{C}(\mathrm{T})$ specimens could be used to account for residual stress effects in the FSW panel. After an equilibrium solution was obtained in the finite element analysis, the panel was analyzed under tensile loading (illustrated in Figure 4), and a residual strength prediction was carried out using crack tip opening angle (CTOA) fracture criteria. A typical 3D finite element model of the 24-inch wide FSW panel containing a through-thickness center crack is shown in Figure 4 with the heat affected FSW zone colored red. The analysis accounted for crack branching, plasticity, variation in panel thickness, residual stress and the presence of multiple materials.

The corresponding load-crack extension data are shown in Figure 5. In the figure, the open and filled symbols correspond to the test data. The black line represents an analysis carried out without considering the effects of residual stress and is shown to over predict the test results. However, by including the residual stress field and change in material properties in the heat-effected zone, the analysis prediction represented by the red line is much better and well within the test scatter. 


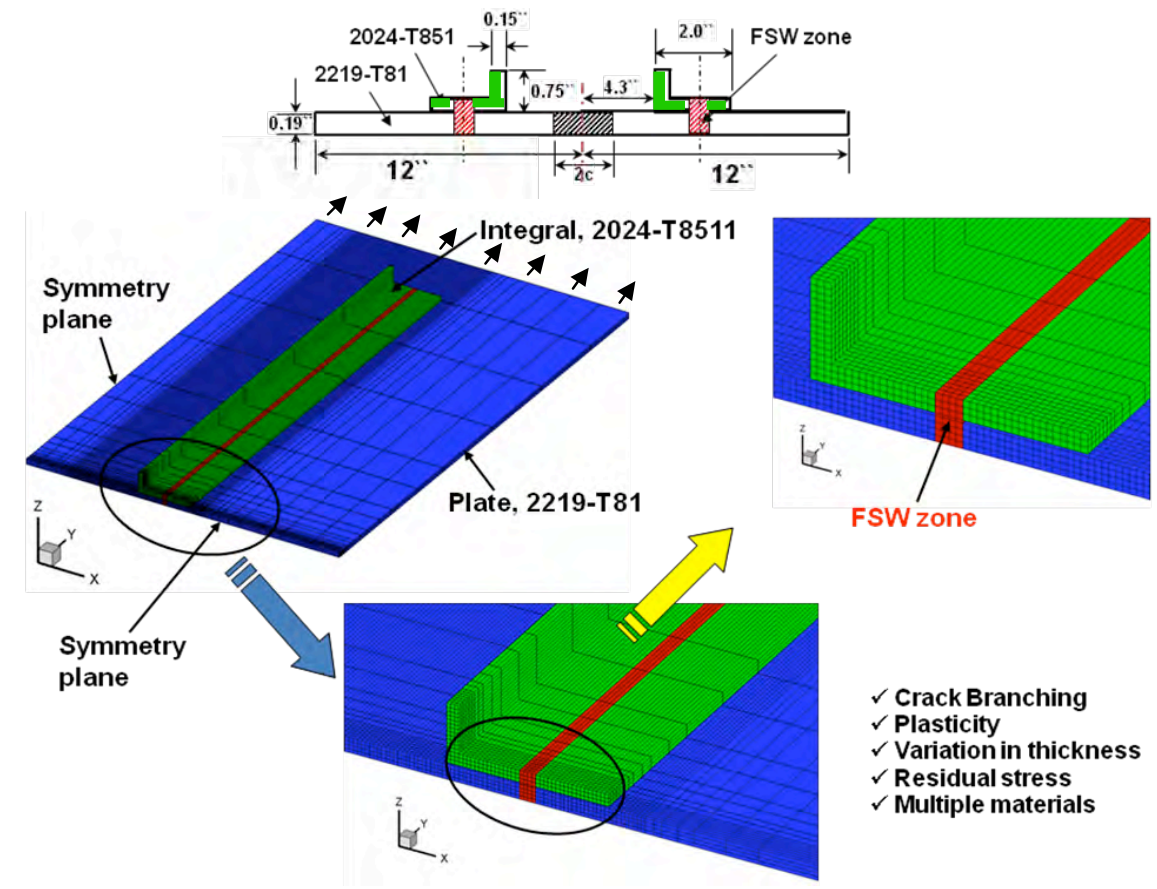

Figure 4: A typical finite element mesh for 24-inch wide FSW integral panel

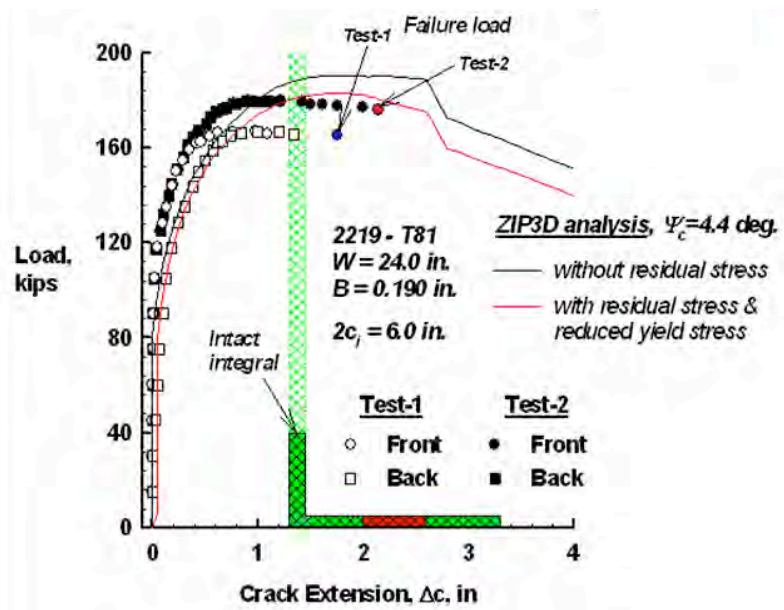

Figure 5: Load-crack extension data for 24-inch wide FSW panel 


\section{Fatigue Crack Growth and Crack Closure}

The most ubiquitous damage in metallic aerospace structures is the slow development and propagation of fatigue cracks during the service life of the aircraft. This process, known as fatigue crack growth, is usually characterized using standardized coupon tests ${ }^{2}$. Fatigue crack growth (FCG) test data are most commonly presented in plots of FCG rate, $\mathrm{d} a / \mathrm{dN}$, (amount of crack growth per number of cycles) as a function of the cyclic cracktip stress intensity factor, $\Delta \mathrm{K}$, as shown in Figure 6 . Three regions are shown, with Region I (the near-threshold region) being of primary concern to the present work. The near-threshold region corresponds to very low values of cyclic crack tip stress intensity factor and is characterized by slow crack growth rates. It is of practical importance for life prediction because the majority of fatigue life for many aircraft components is consumed in this regime.

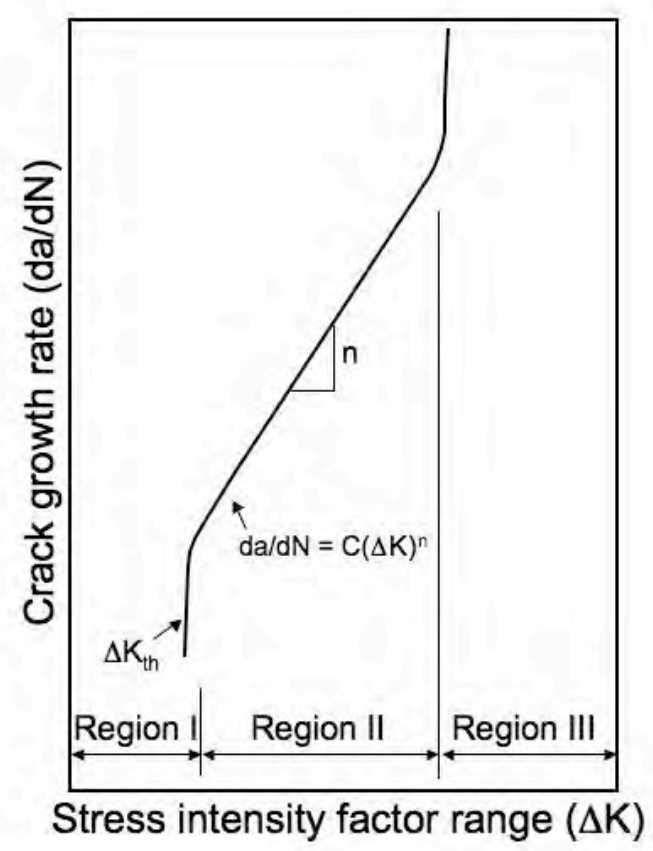

Figure 6: Typical fatigue crack growth behavior

Naturally occurring cracks typically initiate under near-threshold loading conditions and propagate under increasing $\Delta \mathrm{K}$ conditions. However, because of the time required to propagate cracks at low values of $\Delta K$, laboratory tests are typically started in the Paris regime (Region II), and the applied loads are gradually reduced such that $\Delta \mathrm{K}$ values decrease as the crack propagates. The procedure requires that care be taken to ensure that this artificial loading sequence does not affect the fatigue crack growth rate data. As a result, ASTM standard E647 ("Standard Test Method for Measurement of Fatigue Crack Growth Rates") was developed to ensure that satisfactory test results are obtained ${ }^{2}$.

Recent research suggests that performing crack growth tests under $\Delta \mathrm{K}$-reduction conditions can adversely affect the FCG data ${ }^{3,4}$ due to a test-history-induced crack closure phenomenon $^{5-8}$. Fatigue crack closure may result because of crack face contact 
near the crack tip during decreasing load but before the minimum value is reached. Although crack tip closure is a naturally occurring phenomenon, the prescribed load reduction method can induce an artificial "remote closure" that occurs away from the crack tip and can artificially affect the FCG data. Thus, the test data may be affected by the crack tip plasticity created at relatively high $\Delta \mathrm{K}$ near the start of the FCG test and may not be an accurate indication of the mechanical performance of the material.

To assess the effects of testing procedure and the resulting remote closure on FCG data, fatigue crack growth tests were performed using closed-loop servo-hydraulic test machines with constant amplitude sinusoidal loading. Testing was conducted in accordance with ASTM standard E647 using eccentrically-loaded single-edge notch tension $(\mathrm{ESE}(\mathrm{T}))$ specimens ${ }^{9}$ having width, $\mathrm{W}$, and thickness, $\mathrm{B}$, of $38.1 \mathrm{~mm}$ and 2.3 $\mathrm{mm}$, respectively. A schematic of the specimen is shown in the insert in Figure 7. A computer-controlled system ${ }^{10}$ was used to continuously monitor crack length during testing using the back-face compliance technique ${ }^{11}$. This system automatically adjusts the applied loads as the crack grows to ensure that programmed stress intensity factors are applied throughout the tests.

Crack closure data were obtained by analyzing a series of high-magnification (300-700X) digital images of the crack obtained during cyclic loading. A random pattern of $4 \mathrm{~mm}$ speckles was deposited on specimen surfaces in the region of crack growth to provide features whose motion could be tracked as a function of load using the VIC-2D ${ }^{12}$ software program. The presence of crack closure was determined by tracking the relative displacement of speckles on features on either side of the crack. After the digital images were analyzed using VIC-2D, the displacement data was analyzed using the Elber method to determine the load at which the crack closed ${ }^{13}$. In this method, the crackopening displacement at a point along the crack wake is plotted against load resulting in a compliance plot for that specific crack wake location. Deviations in linearity on the plot indicate crack closure.

Preliminary results of this study ${ }^{14}$ demonstrated that remote closure can occur when the testing parameters recommended by ASTM E647 are greatly exceeded. Figure 7 shows the closure profile of an aluminum alloy 8009 specimen tested at constant load ratio, $\mathrm{R}=$ 0.1 , conditions (initial $\mathrm{K}_{\max }=11 \mathrm{MPa} \sqrt{\mathrm{m}}$ and $\mathrm{C}=-393.7 / \mathrm{m}$ ) obtained using VIC-2D. The parameter, $\mathrm{C}$, is the $\mathrm{K}$ gradient and is evaluated as described in Ref. 2. The experimental results of Figure 7 were taken after approximately $3 \mathrm{~mm}$ of crack growth $(\Delta \mathrm{K}=3.3 \mathrm{MPa} \sqrt{\mathrm{m}})$, nearly the $\mathrm{R}=0.1 \mathrm{FCG}$ threshold value for this alloy. Highmagnification images were taken at three locations: near the crack tip, the location corresponding to the start of the $\Delta \mathrm{K}$-reduction test, and further behind the crack tip (corresponding to steady state pre-cracking at $\Delta \mathrm{K}=9.9 \mathrm{MPa} \sqrt{\mathrm{m}}, \mathrm{R}=0.1$ ). This test exceeds the ASTM standard E647 limits on the K-gradient, C, by a factor of 5. Here, remote closure is shown to occur because crack closure occurs in the crack wake before occurring at the crack tip. The horizontal red dashed line in the figure corresponds to the mean normalized closure load $\left(\mathrm{P}_{\text {closure }} / \mathrm{P}_{\max }=0.21\right)$ of the crack wake. In comparison, the crack tip closes later (at a lower load $\mathrm{P}_{\text {closure }} / \mathrm{P}_{\max }=0.12$ ), corresponding to remote closure, and is assumed to be an artifact of the test procedure.

Experimental results also show that the guidelines of ASTM standard E647 are overly conservative for some load scenarios. Figure 8 shows the closure profile (crack closure 
loads as a function of distance behind the crack tip) of a specimen of an aluminum alloy 8009 specimen tested at an initial $\mathrm{K}_{\max }=11 \mathrm{MPa} \sqrt{\mathrm{m}}$ and $\mathrm{C}=-393.7 / \mathrm{m}$. The data presented in Figure 8 correspond to a $\Delta \mathrm{K}=7.4 \mathrm{MPa} \sqrt{\mathrm{m}}$, after $800 \mu \mathrm{m}$ of crack growth from the start of the test. Here, crack closure occurs in the crack wake at approximately $\mathrm{P}_{\text {closure }} / \mathrm{P}_{\max }=0.25$, as indicated by the horizontal red dashed line. Closure loads $\left(\mathrm{P}_{\text {closure }} / \mathrm{P}_{\max }\right)$ increase closer to the crack tip (within $100 \mu \mathrm{m}$ of the crack tip), increasing to approximately $\mathrm{P}_{\text {closure }} / \mathrm{P}_{\max }=0.36$ at the crack tip. In this case, crack closure occurs first at the crack tip with closure occurring in the crack wake at lower loads, in a manner characteristic of steady-state crack closure in the absence of load history effects ${ }^{15}$.
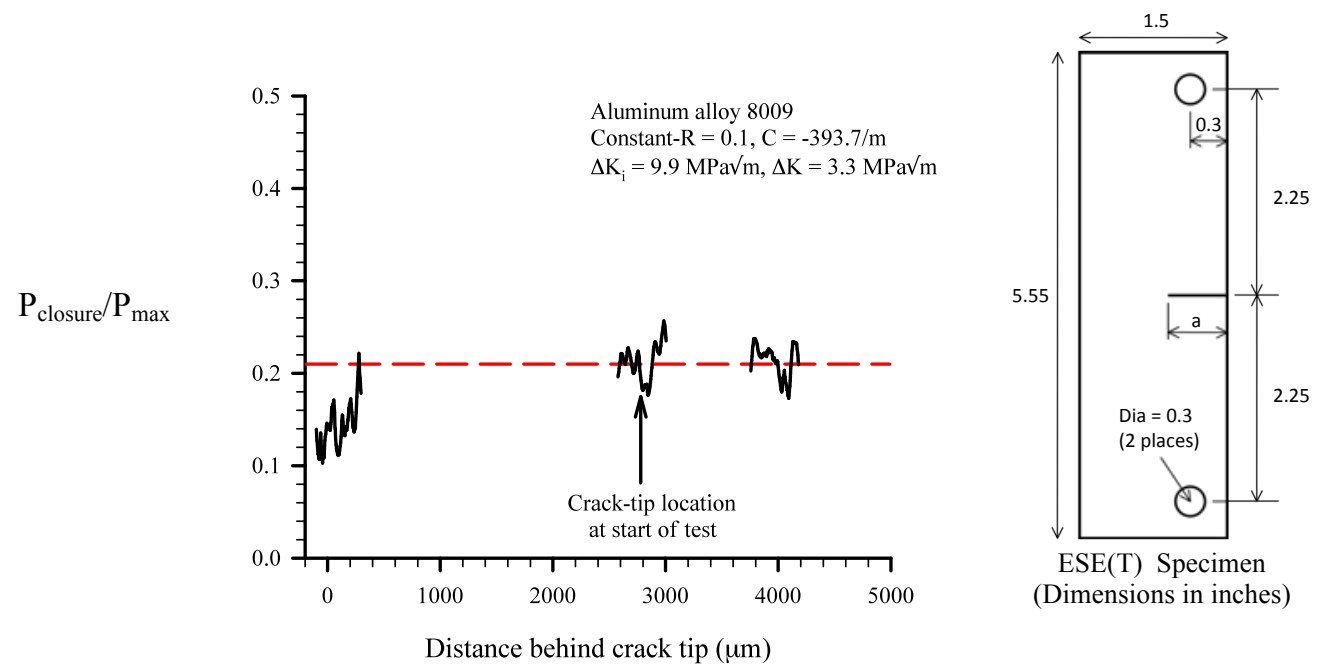

Figure 7: Closure profile for a specimen of aluminum alloy 8009 with initial $\mathrm{K}_{\max }=11$ $\mathrm{MPa} \sqrt{\mathrm{m}}\left(\Delta \mathrm{K}_{\mathrm{i}}=9.9 \mathrm{MPa} \sqrt{\mathrm{m}}\right)$ and $\mathrm{C}=-393.7 / \mathrm{m}$. Remote closure occurs

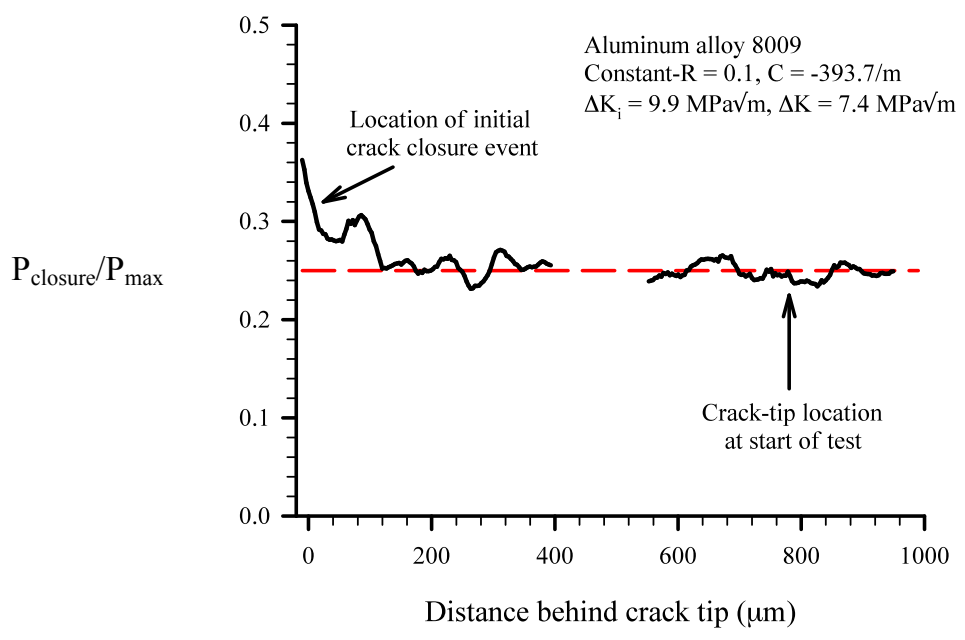

Figure 8: Closure profile for a specimen of aluminum alloy 8009 with initial $\mathrm{K}_{\max }=11$ $\mathrm{MPa} \sqrt{\mathrm{m}}\left(\Delta \mathrm{K}_{\mathrm{i}}=9.9 \mathrm{MPa} \sqrt{\mathrm{m}}\right)$ and $\mathrm{C}=-393.7 / \mathrm{m}$. No remote closure 


\section{Damage Accumulation in Aluminum Microstructures}

The continuum-level behavior discussed previously has its underpinnings at the microand nano-scales, so an understanding of the myriad of microscale and nanoscale mechanisms is needed to fully understand the mechanics of fracture. Thus, Damage Science methodologies are being developed. The work studies phenomena that occur at the scale of grains, dislocations and atoms using novel computational and experimental methodologies.

At the microscale, near-crack-tip plasticity is dominated by the presence of large plastic strain gradients and the corresponding geometrically necessary dislocations (GNDs). The effect of GNDs on conventional plasticity formulations is overviewed by Hutchinson ${ }^{16}$. In this case, a critical issue is the underestimated work hardening during plastic deformation within the strain gradient dominated field. This gives rise to strain gradient crystal plasticity formulations in which GNDs are assumed to dominate micron-scale plastic strain and to be associated with an internal length scale parameter. These gradient formulations are conceptually related to dislocation dynamics (as discussed in an upcoming section), thereby providing a natural linkage to simulations at sub-micron length scales.

Alternatively, conventional crystal plasticity (CCP) formulations can be employed to study material state fields within a microstructure even though they do not accurately capture some aspects of plastic deformation at or below the micron-scale. As with all continuum plasticity formulations, $\mathrm{CCP}$ formulations must be subjected to initial calibration to the particular material at hand. Calibration typically consists of generating a polycrystal model - consisting of a representative population of grain size, aspect ratio, and texture - and matching a simulated response to an observed response by varying several material parameters. The result is a CCP model that is calibrated to incorporate micron scale mechanisms in a homogenized sense.

Even with their quantitative limitations, CCP formulations are being used in conjunction with precise geometrical representations of metallic microstructures to develop a dramatically improved understanding of the sequence of plastic dissipation preceding crack growth at the micron scale. By incorporating models for slip accumulation, a relationship between plastic exhaustion and crack growth can be computed ${ }^{17}$.

To better understand the plastic dissipation during cyclic loading that precedes nucleation events, finite element models were generated using observed microstructural data constituent particles and grain texture and geometry - and slip localization and accumulation was computed near cracked particles ${ }^{18}$. Figures 9 and 10 illustrate the computed slip localization near a cracked constituent particle in aluminum AA 7075T651 for two such models. The contoured fields in both figures are the maximum value of slip on any one of the twelve face centered cubic (FCC) slip systems; the corresponding values given by the contour bars are the magnitude of slip on the dominant system. The particle shown in Figure 9, P50, was observed to nucleate a crack into the surrounding grains, while the particle in Figure 10, P135, did not. It is apparent from these results that slip localization and accumulation (i.e., plastic dissipation) plays a governing role in crack nucleation at this scale; see Reference 17 for further discussion. 
Figures 9 and 10 also show the correspondence between computed slip localization and dominant slip system directions, as measured via electron backscatter diffraction (EBSD). However, the directions of slip localization did not correspond with the nucleation direction, given by the dotted line in Figure 9. This observation leads to a hypothesis for crack trajectory based on alternating shear or maximum tangential stress with neighboring grains. More simulations are currently underway to investigate these hypotheses.
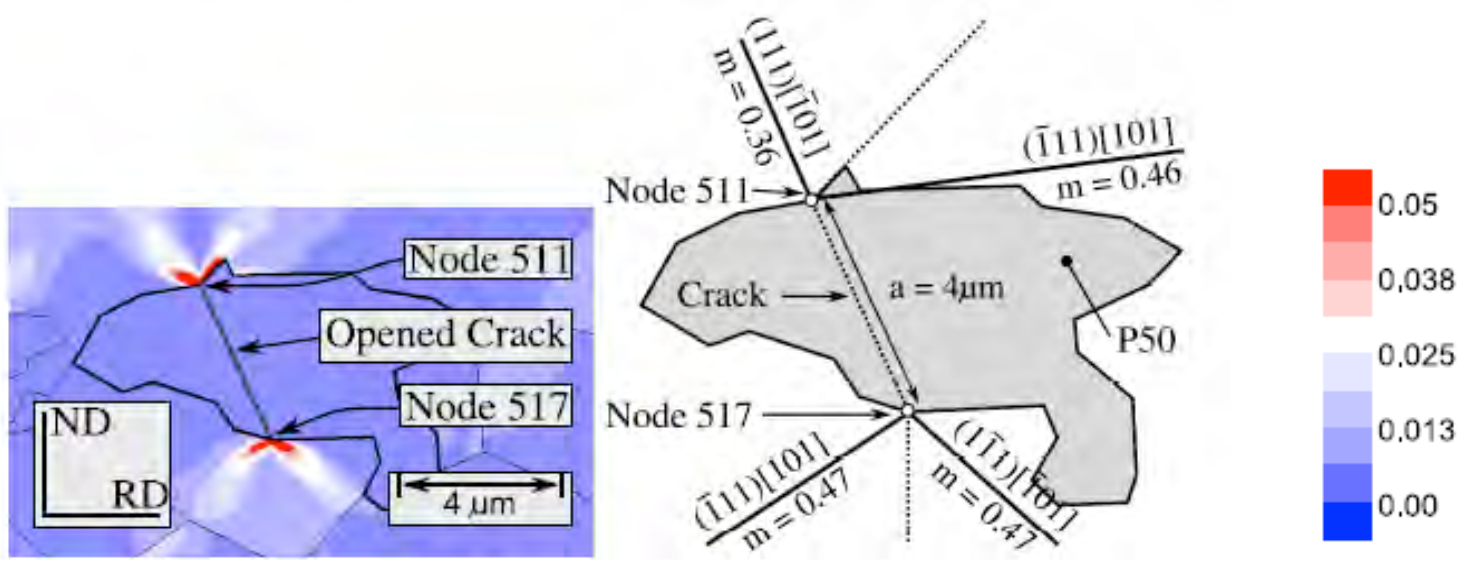

Figure 9. Computed slip fields near a cracked constituent particle that was observed to nucleate a crack into the surrounding grains.
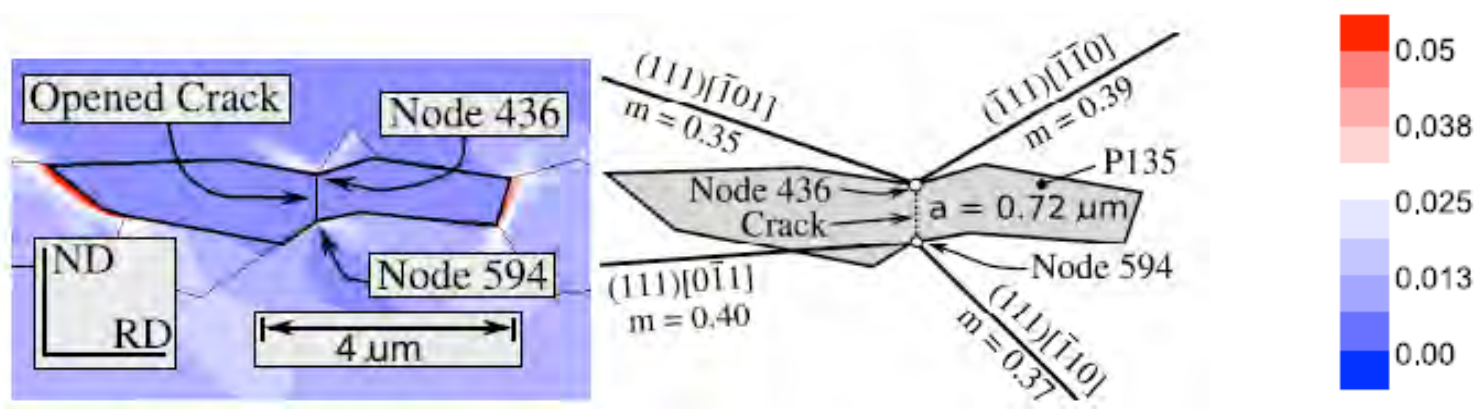

Figure 10: Computed slip fields near a cracked constituent particle that was observed NOT to nucleate a crack into the surrounding grains

\section{Experimental Investigations at the Microscale}

An environmental scanning electron microscope (ESEM) equipped with in situ loading frame and EBSD system has been developed to characterize damage processes in single crystals of pure aluminum and polycrystalline aluminum alloys (Figure 11). The EBSD orientation mapping tools can be used to measure the extent of high plastic deformation near the fatigue crack tip and crack tip wake. Plasticity near the crack tip is related to the plastic strain gradients and thus the geometrically necessary dislocation density.

These dislocations result in bending of the lattice and may be detected as an orientation gradient within a single grain. Additionally, a zone of "significant plastic strain" about a 
fatigue crack tip and crack tip wake can be determined by measuring the width of the highly defected region (e.g., green-to-red rainbow color scheme on misorientation maps). Experimentally determined locations of orientation discontinuities, e.g. at sector boundaries, slip bands, near the crack-tip and GND densities estimated from local lattice rotations can be compared with model predictions to enable the physics-based models to include correct input parameters, such as source and obstacle densities.

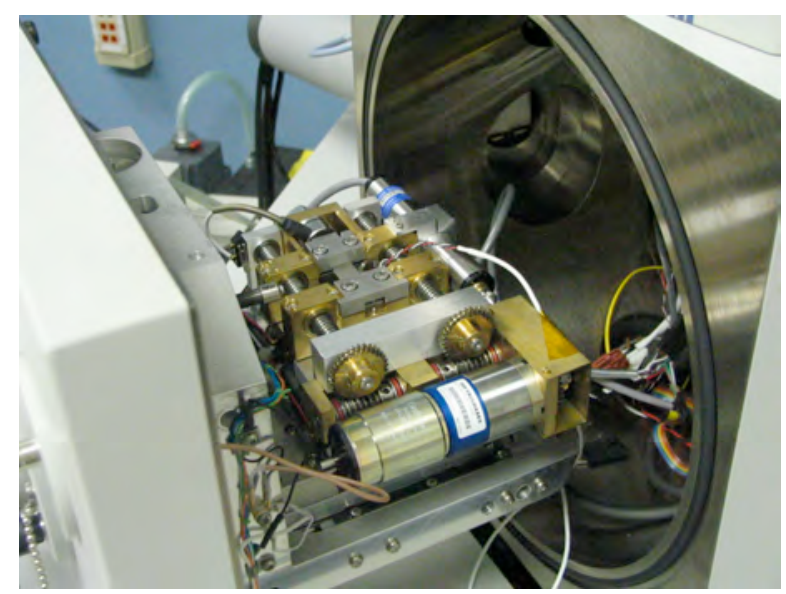

Figure 11: Mechanical loading frame in Environmental Scanning Electron Microscope (ESEM) for the examination of damage propagation at high resolution

Recent studies ${ }^{19,20}$ of single crystals and bicrystals have shown that it is possible to extract some of the components of the Nye dislocation density tensor ${ }^{21}$ using orientation data obtained by EBSD mapping, provided that the crystal orientation and deformation conditions are carefully controlled to constrain the number of independent components. The present work follows References 19 and 20, and considers a connection between the GND content and the lattice curvature tensor through spatially resolved local-orientation measurements using EBSD.

For the purpose of illustration, these approaches have been applied to the EBSD orientation data obtained from the vicinity of a fatigue crack in precipitation-hardened aluminum alloy Al-Cu-Mg 2024-T351. The intra-grain misorientation map (Figure 12a) displays changes in the local orientation, along with large amounts of intra-granular misorientation associated with the large plastic deformation in the vicinity of a crack tip $w_{\text {ake }}{ }^{22}$. White regions in Figure 12a correspond to pixels that were not indexed. The misorientation map reveals distinctions in the morphology of plastic damage, e.g. the presence of slip-bands near the crack tip wake. These maps suggest the presence of a high dislocation content resulting in extensive disorientation.

Figure $12 \mathrm{~b}$ shows the estimated distribution of GND density within the scanned area. The regions of lower dislocation density (i.e., base material, $\sim 0.5-1 \times 10^{14} / \mathrm{m}^{2}$ ) are separated by regions of higher dislocation density (i.e., plastically-deformed crack-wake, $\geq 10^{15} / \mathrm{m}^{2}$ and higher), and can be identified by marked orientation change (Figure 12a) or by the enhanced dislocation density (Figure 12b) ${ }^{22}$. The boundaries of these banded structures (dislocation patterning) contain a high GND density, and regions within the 
bands are relatively free of dislocations that contribute to lattice curvature. An inhomogeneous distribution of the dislocation density becomes obvious for such cases.

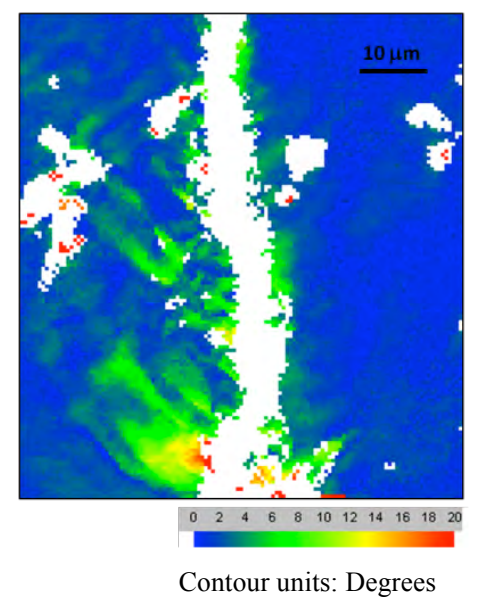

(a) EBSD misorientation map

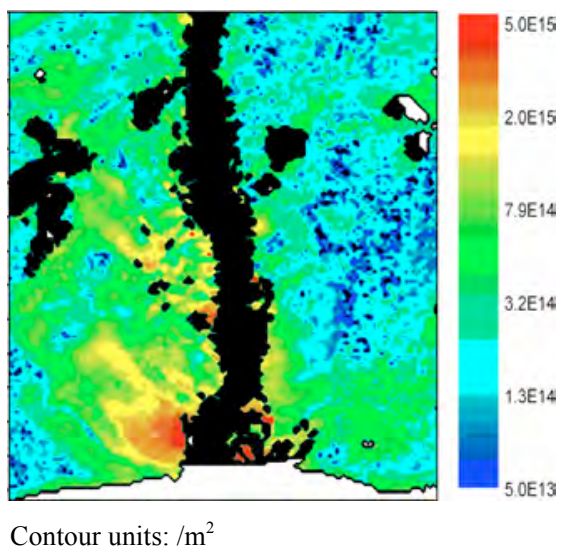

(b) Enhanced dislocation density map

Figure 12: Maps of misorientation and geometrically necessary dislocation density

The measurements of local orientation changes and estimates of GND content near the crack tips and wakes of fatigue cracks can be qualitatively compared with those predicted by computational models developed with the aid of molecular dynamics and finite element simulations. This experimental effort will contribute a significant quantitative and physical understanding of damage mechanisms that will enable next-generation damage models to progress beyond the current empirical models.

In support of experimental studies at the microscale, a comprehensive metallic materials processing facility has been established. This facility enables unique heat treatments of commercially available alloys as well as for the production of idealized microstructures to study specific damage processes. Single and bi-crystalline pure and simple alloy materials are manufactured using either the Czochralski or Bridgman crystal growth methods. The materials are characterized for crystallographic orientation and grain structure and mechanical test specimens are machined to study specific damage processes in specific crystallographic orientations.

\section{Discrete Dislocation Simulation}

Unlike continuum plasticity formulations wherein the elastic-plastic constitutive behavior is assumed, discrete dislocation plasticity approaches have been developed to predict both the plastic stress-strain response and the corresponding evolution of the dislocation structure as part of the solution $^{23}$. Dislocation dynamics (DD) simulation methods have been developed to represent large numbers of dislocations at relatively large length scales compared to atomic dimensions. In these approaches, dislocations are represented as lines of displacement discontinuity where the magnitude of the discontinuity is equal to the Burgers vector. Away from the core region, the displacement, stress and strain fields may be suitably represented by analytic elasticity solutions. Thus, the displacements and 
velocities of individual atoms are not computed. Simulations can involve infinite domains that are modeled using periodic boundary conditions or as finite domains with various prescribed boundary conditions.

In discrete dislocation plasticity, the goal of simulation is often to determine the amount of plastic strain exhibited by a material due to the generation and interaction of the dislocations. For example, Figure 13 depicts the stress-strain response of a single-crystal aluminum loaded in tension using the in-house developed two-dimensional dislocation dynamics code DD-SIM. As shown, both the inelastic plastic yielding together with hardening can be obtained directly from the simulation ${ }^{24}$.

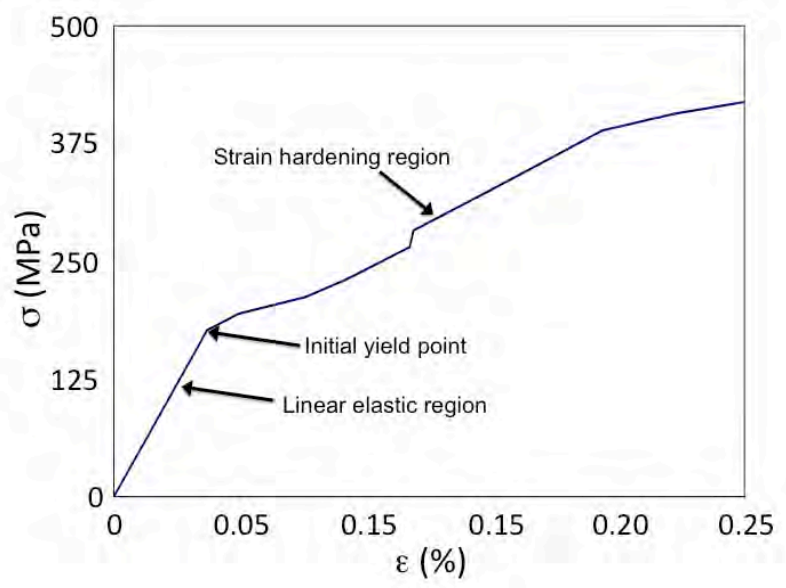

Figure 13: Stress-strain behavior of an aluminum material domain under normal tensile loading

\section{Atomistic Simulation of Crack Growth}

Atomistic simulation of fracture has been a topic of considerable study during the past two decades. Early studies were focused on idealized perfect or non-defect structures, but improved methodologies and increases in computing power are making the study of deformation and fracture in structural materials attainable. Although only very small volumes of material can be studied using atomistic simulation, the studies employ interatomic potentials that are grounded in the results of $a b$ initio calculations and hence give the promise of understanding damage processes at a truly fundamental level (for an overview of atomistic simulation, see Allen and Tildesley ${ }^{25}$ ).

Atomistic simulations are used to determine the fundamental processes of crack initiation and growth including plastic mechanisms (e.g., twinning, dislocations, stacking faults) and the creation of free surfaces (i.e., crack propagation). Because of the extreme computational cost of interrogating large volumes of materials with atomistic simulation, both concurrent and sequential multiscale methods are being developed. The concurrent multiscale methods are developed to dramatically improve computational efficiency by virtually embedding a small (several million atom) atomistic simulation within a large finite element model ${ }^{26}$, whereas the sequential multiscale methods recast the results of the atomistic simulations for use in continuum-based methods ${ }^{27}$. 
Fracture processes in aluminum and aluminum-based alloys are of particular interest. Recently, a number of atomistic simulation studies on intergranular and transgranular crack propagation in aluminum have been published ${ }^{27-31}$. The results of these investigations show that two main mechanisms of crack propagation and plasticity operate at the nano-scale. These mechanisms include propagation through deformation twinning and propagation through the emission of full dislocations from the crack tip (see Figure 14). One major finding of these and other atomistic simulations disagrees with experiment: most atomistic simulations predict deformation twinning as the dominant deformation mechanism whereas experimental observations show that dislocation slip is dominant in aluminum ${ }^{28}$.

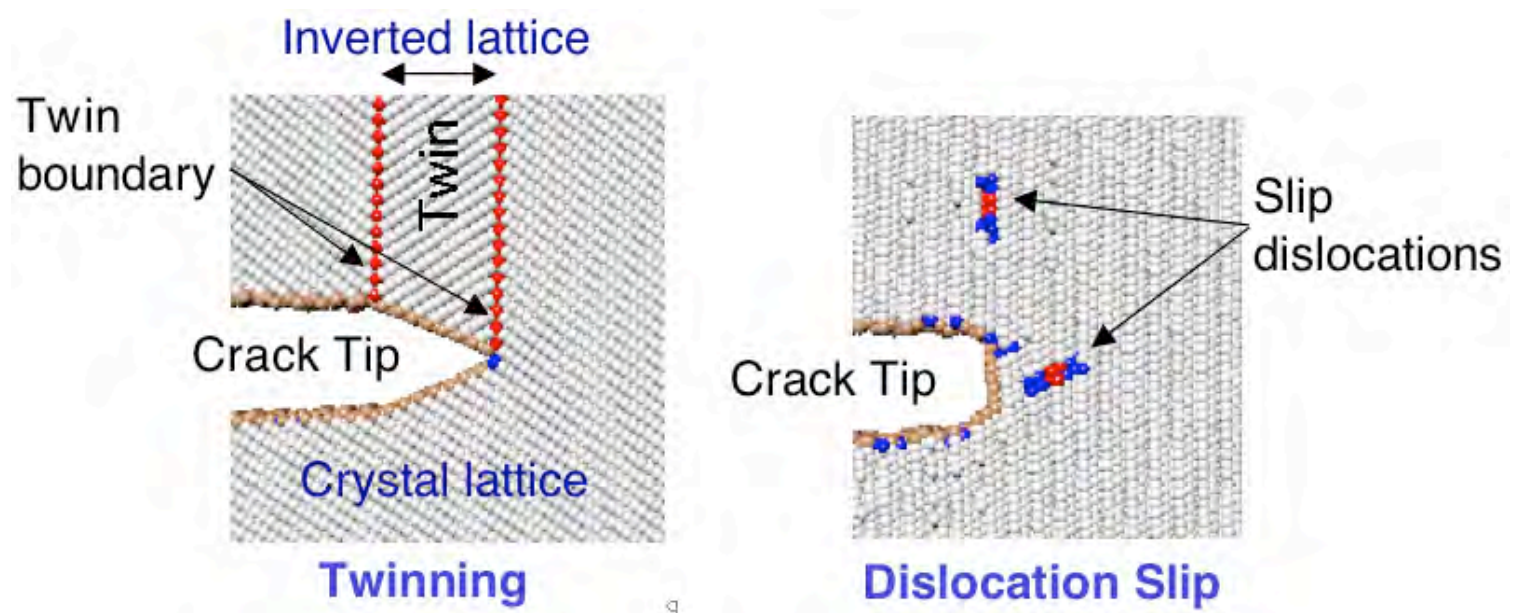

Figure 14: Twinning and slip near a crack tip ${ }^{27}$

The discrepancy between simulations and experiments has attracted considerable attention among researchers because it prevents the reliable and accurate modeling of fracture in particular and puts doubt on the reliability of the atomistic simulations in general $^{17,31}$. Most likely, the source of this discrepancy is related to the very different length (nanometers vs. millimeters) and time (nanoseconds vs. seconds) scales at which simulations and experiments are usually performed. Nonetheless, the exact mechanism of how these length and time scales affect the propagation process remains unclear and is a very active topic of research.

To improve the understanding of the sources of the discrepancy between simulation and experiment, a detailed study has been undertaken to determine the conditions under which twinning or dislocation emission occur at a crack tip under Mode I loading ${ }^{32}$. The recently developed embedded statistical coupling method $(\mathrm{ESCM})^{26}$ for concurrent multiscale modeling was used. Studying the crack tip nucleation process at different crack orientations and loads revealed the existence of a transition stress intensity, $K_{\mathrm{IT}}$, below which the crack emits full dislocations, and above which deformation twinning becomes dominant. The transition stress intensity was found to depend on the crystallographic orientation and temperature. This understanding of the competition between the two mechanisms under the conditions of an atomistic simulation will enable determination of the regimes that are most suitable for study using these methods. 


\section{Fracture Mechanics of Composite Materials}

The focus of much of the work conducted in the branch on composite materials has centered on the investigation of the damage tolerance capabilities of laminated composites and sandwich composites. A long-established theme of this work has been the development of standardized testing practices for characterizing failure modes of composite laminates, such as a double cantilever beam test ${ }^{33}$ for measuring mode I delamination resistance, and a curved beam test ${ }^{34}$ for measuring the interlaminar strength of composite laminates. Efforts have also focused on computational methods for simulating failure mechanisms, geared towards improving the design and certification of structure manufactured from composite materials. The work was performed in support of a number of NASA aeronautics-related programs and has included collaborative efforts with major domestic airframe manufacturers.

\section{Mode I Fatigue Delamination Round Robin}

An ASTM International Round Robin test exercise ${ }^{35}$ is being conducted to develop a standard test method for mode I fatigue delamination propagation in unidirectional fiberreinforced polymer matrix composites. Round Robin participants include six different laboratories in three countries. The goal of this Round Robin is to develop a standard test method for determining delamination growth rate under constant amplitude fatigue loading as a function of the cyclic strain energy release rate, $G_{\text {Imax }}$.

The Round Robin uses the double cantilever beam (DCB) specimen, shown in the inset in Figure 15 , to determine the delamination growth rate, da/dN, of three different laminated composite materials ${ }^{35}$. Currently, standards exist for using the DCB specimen to determine mode I fracture toughness, $G_{I c}$, (ASTM International Standard D5528) ( $^{33}$ and $G_{\text {Imax }}$ for delamination onset under cyclic loading (ASTM International Standard $\mathrm{D} 6115)^{36}$.

Prior to fatigue testing, static DCB tests were conducted on the test materials, using ASTM Standard D5528, to determine critical displacement levels corresponding to delamination onset and data reduction constants for the fatigue tests. There is an artificial increase in the fracture toughness because the DCB specimen experiences fiber bridging as the delamination grows. The resulting curve of toughness vs. crack length, known as an R-curve, is shown in Figure 15, where a polynomial expression has been fit to the static data. In order to account for the effect of fiber bridging in the fatigue tests, the fatigue data are normalized by this R-curve expression ${ }^{35}$.

Fatigue tests were conducted in displacement control using an R-ratio of 0.1 and a frequency of $10 \mathrm{~Hz}$. For DCB specimens under displacement control, da/dN decreases as the delamination grows. To obtain the complete da/dN curve, tests were run at a $G_{\text {Imax }}$ level just below $G_{I c}$ and allowed to continue until delamination arrested or until $d a / d N$ was $10^{-6} \mathrm{~mm} /$ cycle or less. Figure 16 shows results of the fatigue testing of five specimens of one material where the applied $G_{\text {Imax }}$ has been normalized by the plateau value of the R-curve $\left(G_{I R}\right)$. Delamination growth rates were consistent for all five 
specimens. Typically, a power law expression of the form $d a / d N=A\left(G_{\operatorname{Imax}} / G_{I R}\right)^{n}$ is fit to this data plot, as shown in the figure. The purpose of the round robin exercise is to streamline the test protocol to ensure that the test yields reliable fatigue delamination growth data ${ }^{35}$.

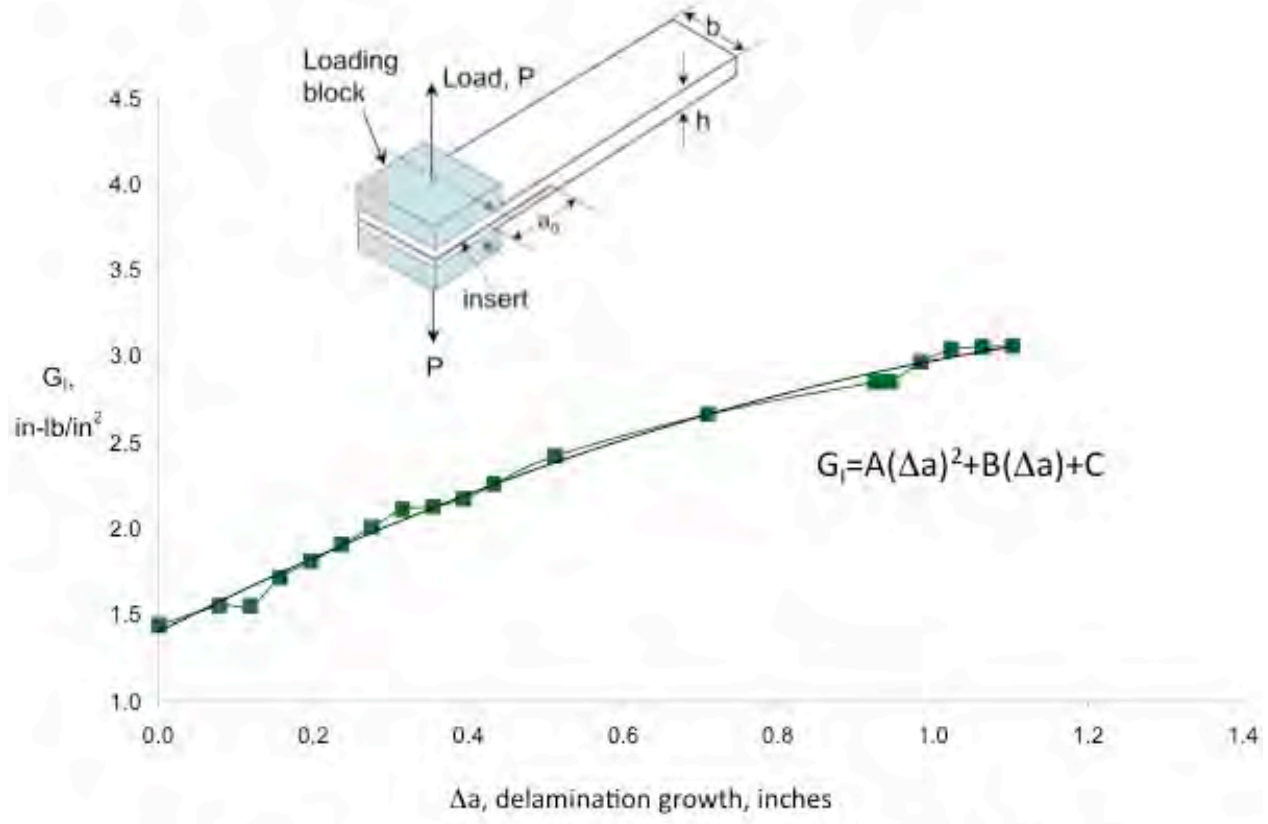

Figure 15: Delamination resistance curve (R-curve) and DCB specimen

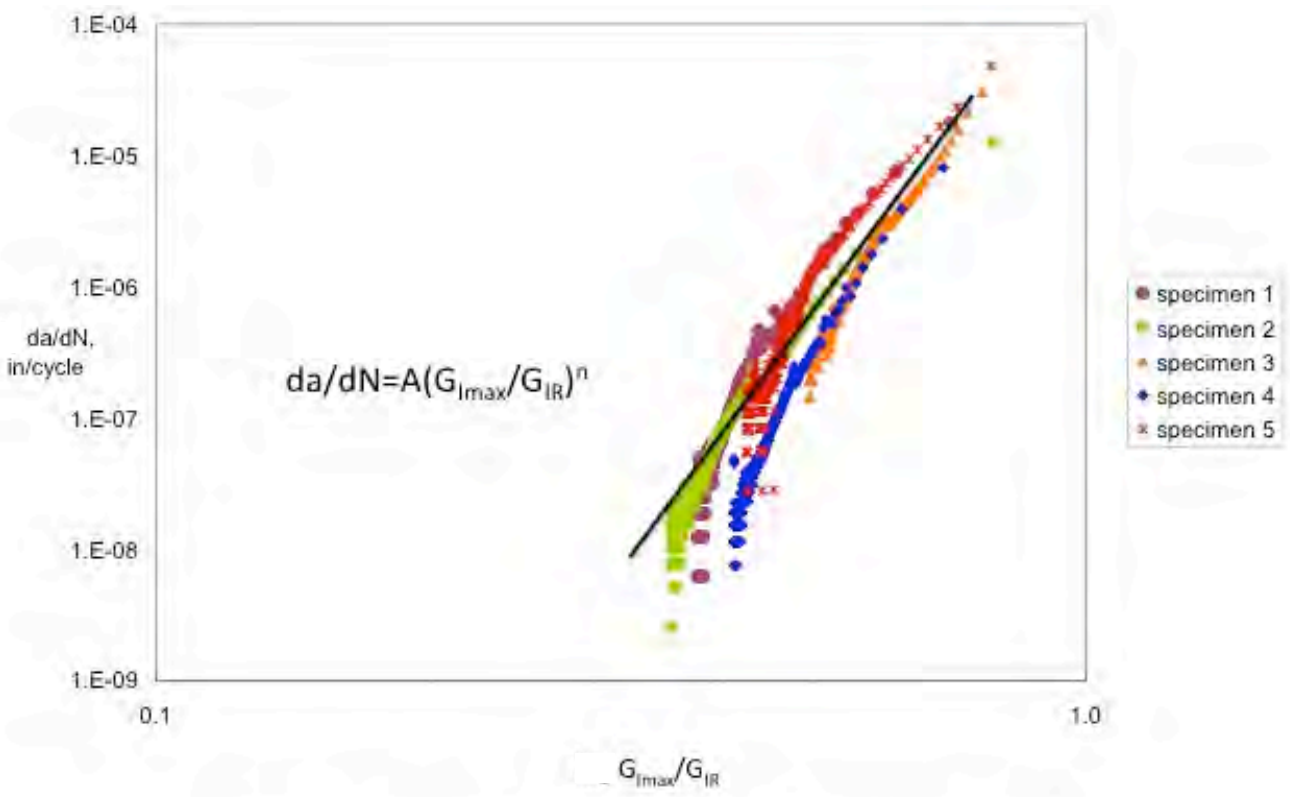

Figure 16: Delamination growth rate data normalized by R-curve 


\section{Analysis Benchmarking}

Over the past two decades, the use of fracture mechanics has become common practice for characterization of the onset and growth of delaminations. In order to predict delamination onset or growth, the calculated strain energy release rate components are compared to interlaminar fracture toughness properties measured over a range from pure mode I loading to pure mode II loading, using delamination growth characterization tests similar to the specimen discussed in the previous section.

The virtual crack closure technique (VCCT) is widely used for computing energy release rates based on results from 2D and 3D finite element analyses and for supplying the mode separation required when using a mixed-mode fracture criterion ${ }^{37}$. The VCCT procedure was recently implemented in the commercial finite element codes ABAQUS ${ }^{\circledR}$, MSC Nastran ${ }^{\circledR}$ and Marc. ${ }^{\mathrm{TM}}$ These implementations must be benchmarked to ensure that the method reproduces accurately reference solutions.

An approach for assessing the delamination propagation capabilities in commercial finite element codes under static loading was demonstrated for VCCT for ABAQUS ${ }^{\circledR 38}$. First, full three-dimensional finite element models of the Single Leg Bending (SLB) specimen shown in Figure 17 were developed. Second, starting from an initially straight front, a benchmark solution that involved manual nodal release and computation of fracture parameters using VCCT was developed. Third, the commercial implementation was executed on an identical configuration. Comparison of the load-displacement relationship and the total strain energy release rates obtained from the commercial implementation and the benchmark solution showed that good agreement could be achieved by selecting the appropriate input parameters as shown in Figure 18. Selecting the appropriate input parameters, however, was not straightforward and often required an iterative procedure. Overall, the results are encouraging but further assessment on a structural level is required.

Ongoing efforts include the application of the recently developed benchmark examples to the commercial finite element codes MSC Nastran ${ }^{\mathrm{TM}}$ and Marc ${ }^{\mathrm{TM}}$. Additionally, new benchmark examples are being created. The focus is on the assessment of the delamination growth prediction capabilities in commercial finite element codes when the specimen is subjected to cyclic loading. 


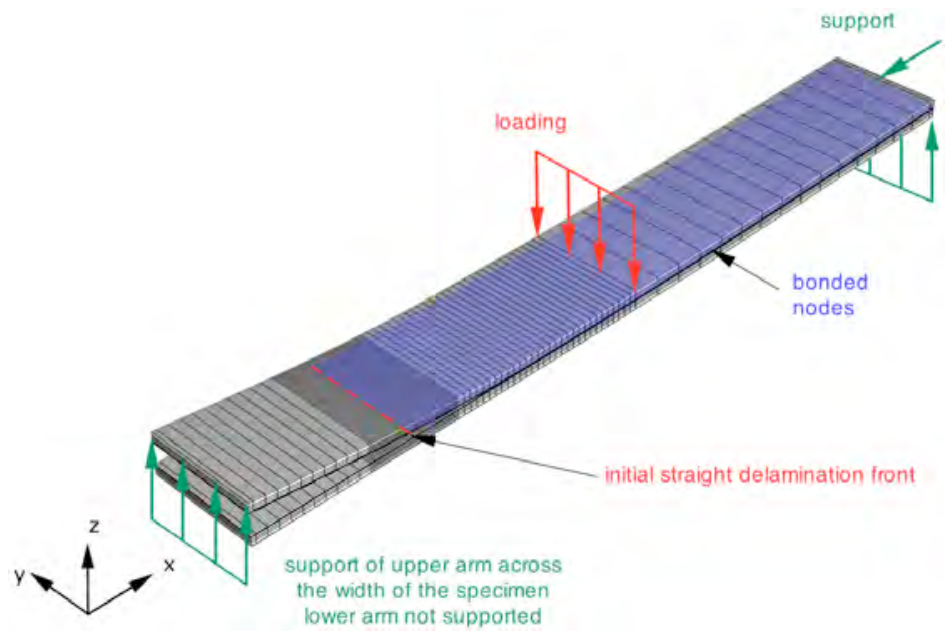

Figure 17: Finite element mesh of a single leg-bending (SLB) specimen

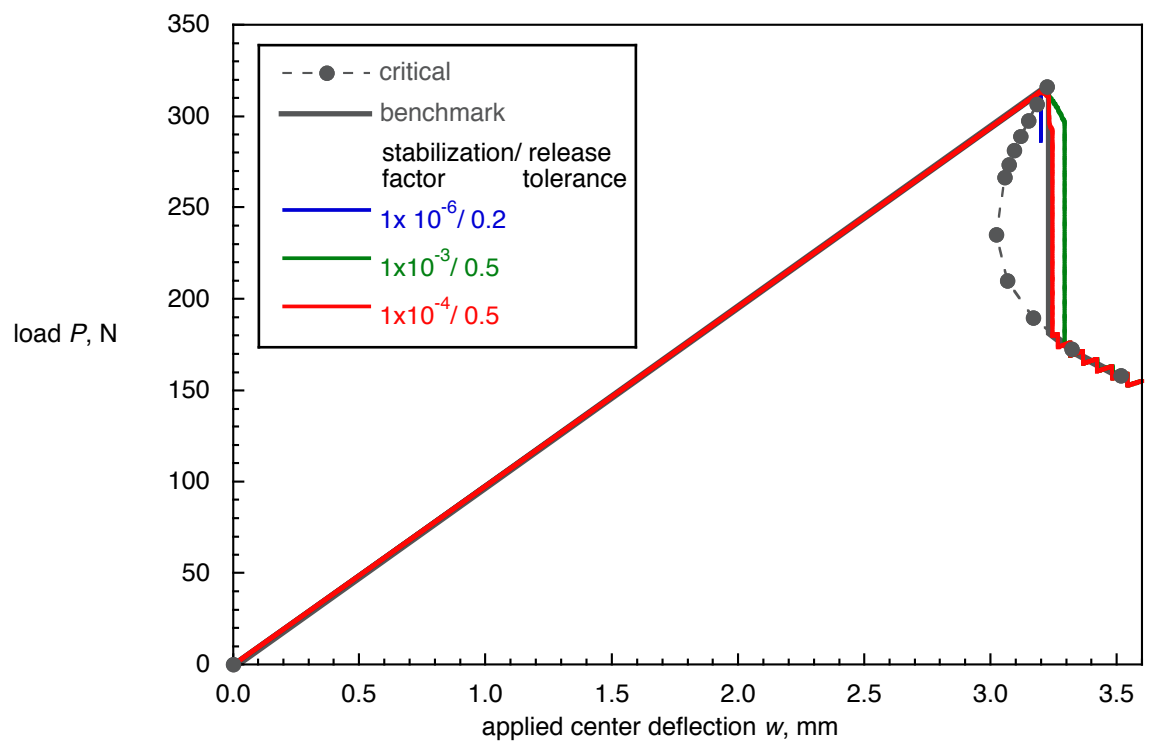

Figure 18: Force-displacement response used in benchmarking procedure

\section{Predicting Delamination Growth in Z-Pin-Reinforced Laminates}

The previous two activities focused on methods for characterizing and analyzing delamination growth in composite laminates. Work has also been conducted to evaluate new methods for enhancement of the delamination resistance of a laminate. A number of techniques have been developed previously to achieve this enhancement, including stitching $^{39}$ and a process known as z-pinning ${ }^{40}$. Both methods involve the placement of fibers through the thickness of a laminate for the purpose of providing closure tractions to delaminations. In the case of z-pinning, pultruded carbon rods, available in diameters ranging from 0.25 to $0.5 \mathrm{~mm}$, are placed into an uncured component using an ultrasonic 
hammer, as illustrated in Figure 19a. An example of z-pins bridging the delamination in a DCB specimen is pictured in Figure 19b.

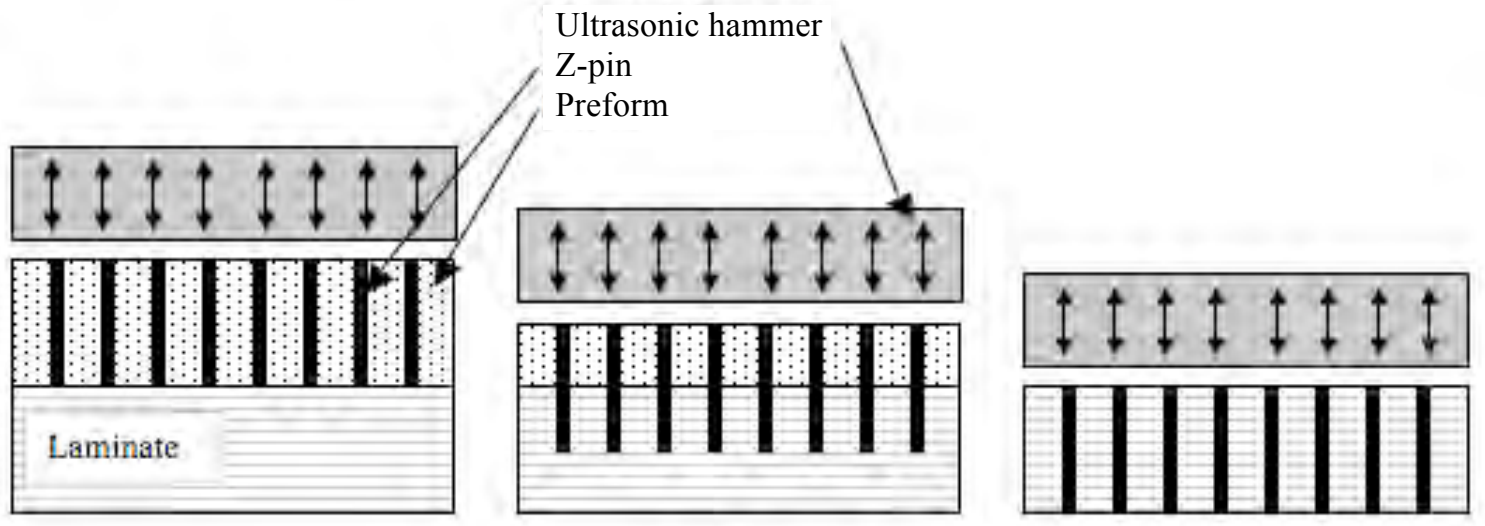

(a) Z-pin insertion process

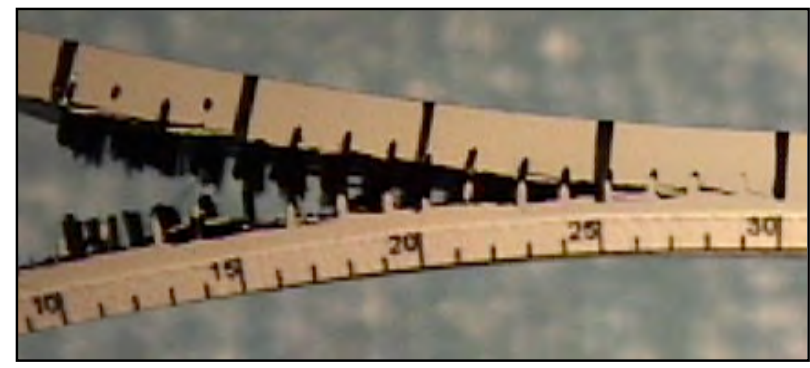

(b) Z-pins bridging a delamination

Figure 19: Z-pin insertion process and example of z-pins bridging a delamination

As a delamination proceeds through a z-pin reinforced laminate, the pins first provide elastic closure tractions that oppose the delamination process until the bond between the pins and surrounding laminate begins to fail, after which the pins pull out from one side of the delaminating sections. A laminate showing debonded and partially debonded zpins is shown in Figure 19b. Subsequently, any analysis that aims to predict delamination growth under such circumstances must include the $z$-pin failure mechanisms. A recent analysis method ${ }^{41}$ that modeled the DCB specimen as a cantilever beam, and the bridging z-pins as a series of springs is illustrated in Figure 20a.

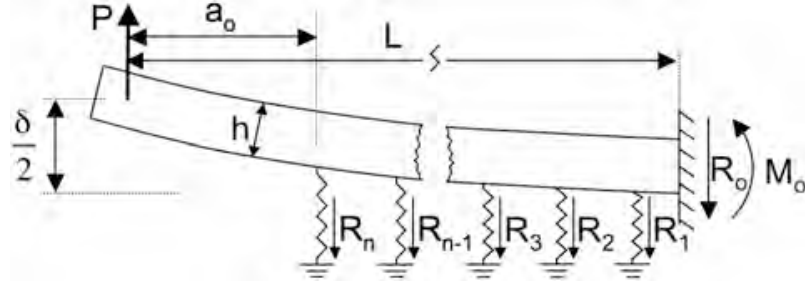

(a) Model of DCB specimen

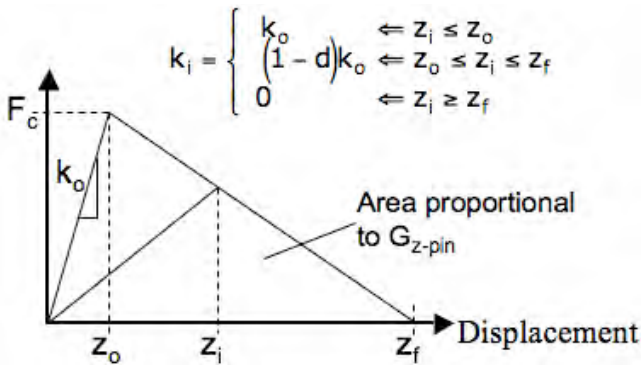

(b) Constitutive z-pin failure law

Figure: 20: Model of DCB specimen reinforced with z-pins 
The analysis results in a closed-form solution of the specimen stiffness vs. delamination length relationship, expressed generally as ${ }^{41}$ :

$$
C_{n}=\frac{\delta_{n}}{P}=2\left[\frac{a_{o}^{3}}{3 E I}+\frac{L^{3}-a_{o}^{3}}{3 E_{z p} I_{z p}}\right]+\frac{1}{3 P E_{z p} I_{z p}}\left[\sum_{i=1}^{n} k_{i} z_{i} a_{i}^{2}\left(a_{i}-3 L\right)\right]
$$

where $E I$ is the flexural rigidity of the beam. The other terms in Eq. 1 are illustrated in Figure 20. The solution to Eq. 1 requires an iterative procedure in order to account for the bi-linear constitutive law that is employed to represent the z-pin failure mechanism and is illustrated in Figure 20b. Once Eq. 1 is solved for a range of delamination lengths, the apparent debond toughness is computed using linear elastic fracture mechanics. The analysis was used to study the effect of z-pin spacing on delamination growth in the DCB specimens, and also to estimate the enhancement in fracture toughness relative to the parent material. This and other studies ${ }^{42,43}$ indicated that small areal densities of z-pins, on the order of $1.5 \%$, can increase delamination resistance by an order of magnitude. It is noted however that the inclusion of z-pins in a laminate can negatively affect some inplane properties, which must therefore be evaluated when z-pins are being considered for use. An example of work performed in the branch on this topic follows in the proceeding section.

\section{Influence of Fiber Misalignment due to Z-pins on the Compressive Response of Composite Laminates}

Although the toughening properties of stitches, z-pins and similar structures have been studied extensively, only a few investigations have focused on the effect of z-pins on the in-plane properties of laminates. Steeves demonstrated that disruption in the alignment of the fibers in the composite leads to a significant reduction in the in-plane compressive strength $^{44}$. The z-pins may cause significant misalignment of the fibers (see Figure 21) of the composite because the diameter of the z-pins $(\sim 280$ to $510 \mu \mathrm{m})$ is large relative to the diameter of the fibers $(\sim 7 \mu \mathrm{m})$. Previously, Sun and coworkers studied the influence of shear loads on the uni-axial compression strength of composites by testing an off-axis unidirectional lamina and extrapolating the compression strength ${ }^{45,46}$. They found that the addition of small shear loads significantly reduce the compression strength of unidirectional composite lamina.

Therefore, the influence of compression and shear loads on the strength of composite laminates with z-pins was evaluated parametrically using a 2D Finite Element Code $(\text { FLASH })^{47}$ based on Cosserat couple stress theory ${ }^{48,49}$. Meshes of unit cells were generated for three unique combinations of z-pin diameter and density ${ }^{50}$. First, a laminated plate theory analysis was performed on several layups to determine the bi-axial stresses in the zero degree plies. Second, these stresses were used to determine the magnitude of the relative load steps prescribed in the FLASH analyses. Results indicated that increasing pin density was more detrimental to in-plane compression strength than increasing pin diameter. Compression strengths of lamina without z-pins agreed well with a closed form expression derived by Budiansky and Fleck ${ }^{51}$. FLASH results for lamina with z-pins were consistent with the closed form results, and FLASH results without z-pins, if the initial fiber waviness due to z-pin insertion was added to the fiber waviness in the material to yield a total misalignment. The addition of $10 \%$ shear to the 
compression loading significantly reduced the lamina strength compared to pure compression loading. The addition of 50\% shear to the compression indicated shear yielding rather than kink band formation as the likely failure mode. Two different stiffener reinforced skin configurations with z-pins, one quai-isotropic and one orthotropic, were also analyzed. Six unique loading cases ranging from pure compression to compression plus $50 \%$ shear were analyzed assuming material fiber waviness misalignment angles of 0,1 , and 2 degrees. Compression strength decreased with increased shear loading for both configurations, with the quasi-isotropic configuration yielding lower strengths than the orthotropic configuration ${ }^{50}$.

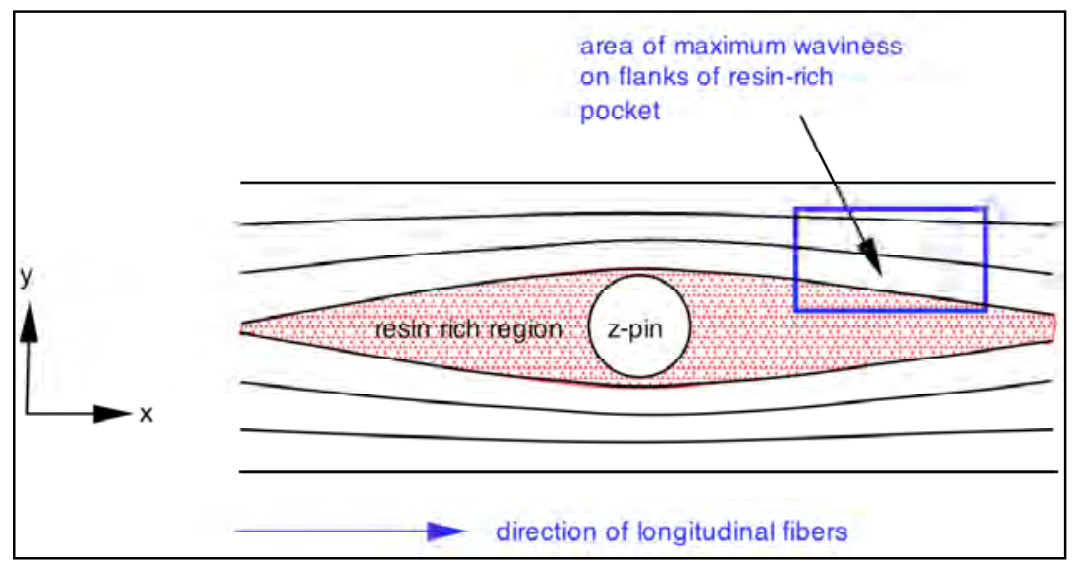

Figure 21: Disruption of fiber alignment due to presence of a z-pin

\section{Designing Specimens for Characterizing Facesheet-Core Debonding in Sandwich Structure}

Other activities at NASA Langley examine the damage tolerance capabilities of sandwich structure, with particular attention paid to sandwich employed in rotorcraft, as discussed in the following two sections. A recent activity, in support of NASA's Subsonic Rotary Wing Program and in collaboration with researchers from the University of Utah, is focused on the development of a standardized testing protocol for characterizing facesheet-core peel debonding in sandwich structure. The purpose of the test is to determine the critical strain energy release rate, $G_{c}$, associated with the facesheet-core debonding process. Following the recent identification of an appropriate test specimen ${ }^{52}$, namely the single cantilever beam (SCB) illustrated in Figure 22, a procedure was developed for determining appropriate dimensions of the specimen ${ }^{53}$.

The specimen sizing method is based on the beam-on-elastic-foundation model of the SCB specimen, depicted in Figure 22. Subsequent analysis yields a closed-form solution of the stiffness-debond length relationship of the SCB specimen, which is used in the computation of $G_{c}$, and is expressed as ${ }^{54}$ :

$$
C_{S C B}=\frac{\delta}{P}=\frac{4 \lambda}{k}\left[\frac{\lambda^{3} a^{3}}{3}+\lambda^{2} a^{2} F_{1}+\lambda a F_{2}+\frac{3 a k}{10 \lambda G_{x z, f} t_{f} b}+\frac{F_{3}}{2}\right]
$$


See Reference 53 for a complete description of Eq. 2. This relationship is simplified to a format that is acceptable for use in a standardized testing protocol by imposing limitations on the SCB specimen dimensions, thereby resulting in the specimen design method (details of the limitations imposed on the SCB specimen can be found in Reference 53). With these limitations imposed, the stiffness-debond length relationship simplifies to ${ }^{53}$ :

$$
C_{S C B}=\frac{4}{E_{f} b t_{f}^{3}}\left[a+\frac{1}{\lambda}\right]^{3}
$$

In addition to obtaining the desired stiffness-debond length relationship, the sizing method is also geared to result in specimens that behave in a linear-elastic manner, as required by the procedures used for computing $G_{c}$ from the test data. The sizing method will form part of the standardized testing protocol, developed under ASTM International's committee on composite materials, D30.

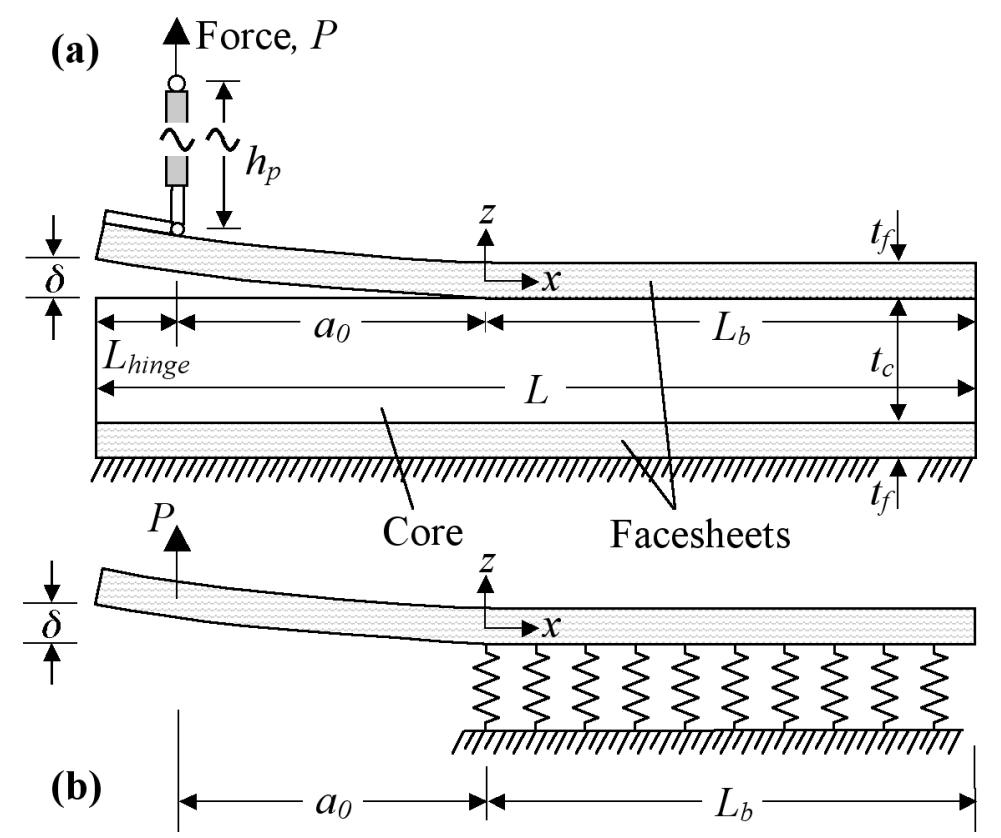

Figure 22: Schematic and beam-on-elastic-foundation model of the SCB specimen

\section{Predicting the Residual Compressive Strength of Impact-Damaged Sandwich Panels} In addition to being susceptible to delamination, sandwich composite materials are very susceptible to damage from out-of-plane loading, including low-velocity impact. These structures must be designed to sustain ultimate load with barely visible impact (BVID) damage. BVID can result in a compressive strength reduction of $50 \%$ or more relative to an undamaged structure ${ }^{55}$. Subsequently, a series of edgewise compression tests were conducted to identify mechanisms involved in the compressive failure of impactdamaged sandwich panels, and analysis methods were developed to predict residual compressive strength of impact-damaged sandwich panels, as detailed in this section. 
In order to measure the residual compressive strength of impact-damaged sandwich panels, the specimens are subjected to an axial compressive load using a test configuration similar to that shown in Figure 23. Specimens subjected to this test have been observed to fail via one of two distinct failure modes ${ }^{55}$, namely kink-band propagation or indentation growth. Figure 24 shows shadow moiré images of failure sequences from the two failure modes. With kink-band propagation (Figure 24a), the damage acts as a stress concentration similar to an open hole. As a compressive load is applied, the tows or fibers in the loading direction buckle and break normal to the plane of the facesheet, creating a band of broken fibers (on both sides of the impact damage) that propagates perpendicular to the loading direction. This kink-band continues to stably propagate away from the damaged region with increasing load until a critical length is reached where the kink band becomes unstable, resulting in panel failure. For the indentation-growth failure mode (Figure 24b), the residual indentation from the impact buckles inward and expands as the compressive load increases. The local buckle in the facesheet applies compressive loads to the core, causing additional crushing as well as elastic deflections. When a critical compressive force is reached, the facesheet rapidly buckles across the width and fails.

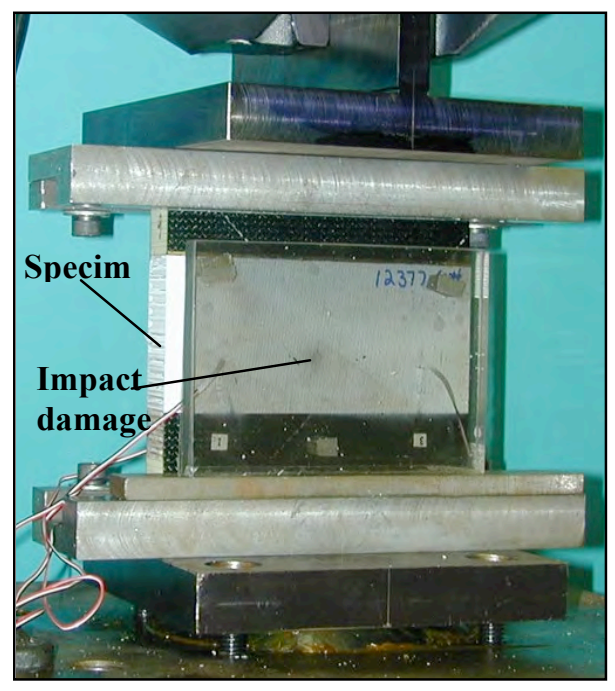

Figure 23: Edge-wise compression test on an impact-damaged sandwich panel 


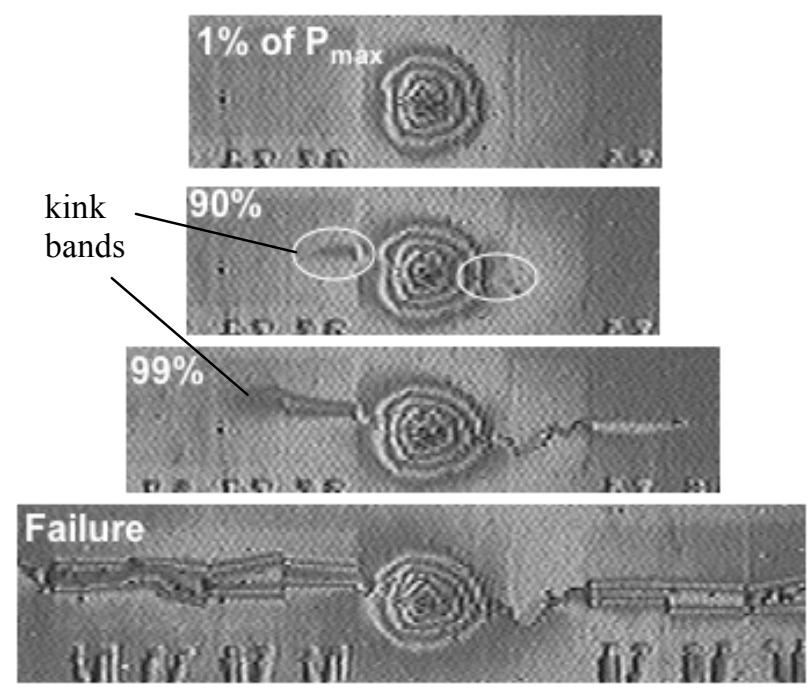

(a) Kink-band propagation

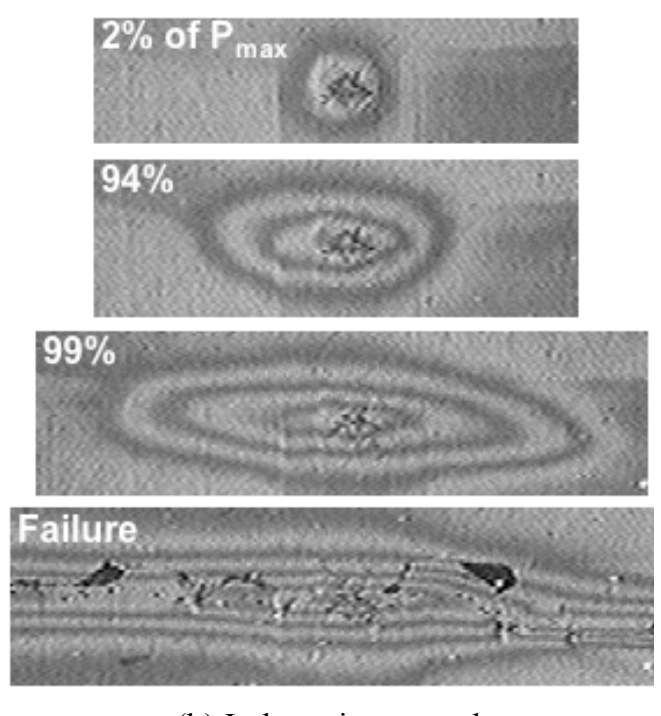

(b) Indentation growth

Figure 24: Examples of compressive failure modes $\left(\mathrm{P}_{\max }\right.$ denotes force at panel failure

Two separate analysis methods have been developed to predict the residual compressive strength of panels that exhibit either the kink-band or indentation-growth failure mode. The method tailored towards the former failure mode proceeds in two parts ${ }^{56}$, and is a modification to a previous analysis ${ }^{57}$ designed for predicting the residual compressive strength of impact-damaged, monolithic laminates. In the first part, the far-field stress required for stable kink-band growth is computed by modeling the damaged facesheet as an orthotropic plate with an open hole, Figure 25. This computation is repeated for a range of kink-band lengths and plotted as illustrated in Figure 25. In the second part, the far-field stress required for unstable kink-band growth is computed using linear elastic fracture mechanics, where the apparent fracture toughness associated with kink-band growth is measured using the compact-compression test pictured in Figure 25. This computation is repeated for a range of kink-band lengths and superimposed onto the plot of far-field stress for stable kink-band growth. Given that panel failure is actually observed when kink-band growth transitions from stable to unstable conditions, the intersection of the plots in Figure 25 is deemed to correspond to the residual strength of the panel.

The method for predicting residual compressive strength of sandwich panels exhibiting the indentation-growth failure mode involves a finite element model of the impactdamaged facesheet and core material ${ }^{58}$. The facesheet is modeled using shell elements, with the impact damage represented as a residual indentation, as depicted in the sample mesh shown in Figure 26. The core material is represented using 2-node spring elements. Idealized constitutive traction laws shown in Figure 26 are assigned to the spring elements to represent the crushing response of the core material during the compression test. These traction laws are based on the crush response of honeycomb structure subjected to flat-wise compressive loading. The finite element analysis is executed using the loading and boundary conditions illustrated in Figure 26. The global forcedisplacement response is computed at the end of each increment of the analysis. An 
example of a typical force-displacement response is presented in Figure 27, where the maximum force is deemed to correspond to panel failure (on the basis of experimentally observed force-displacement response), and is thus used to compute residual compressive strength.

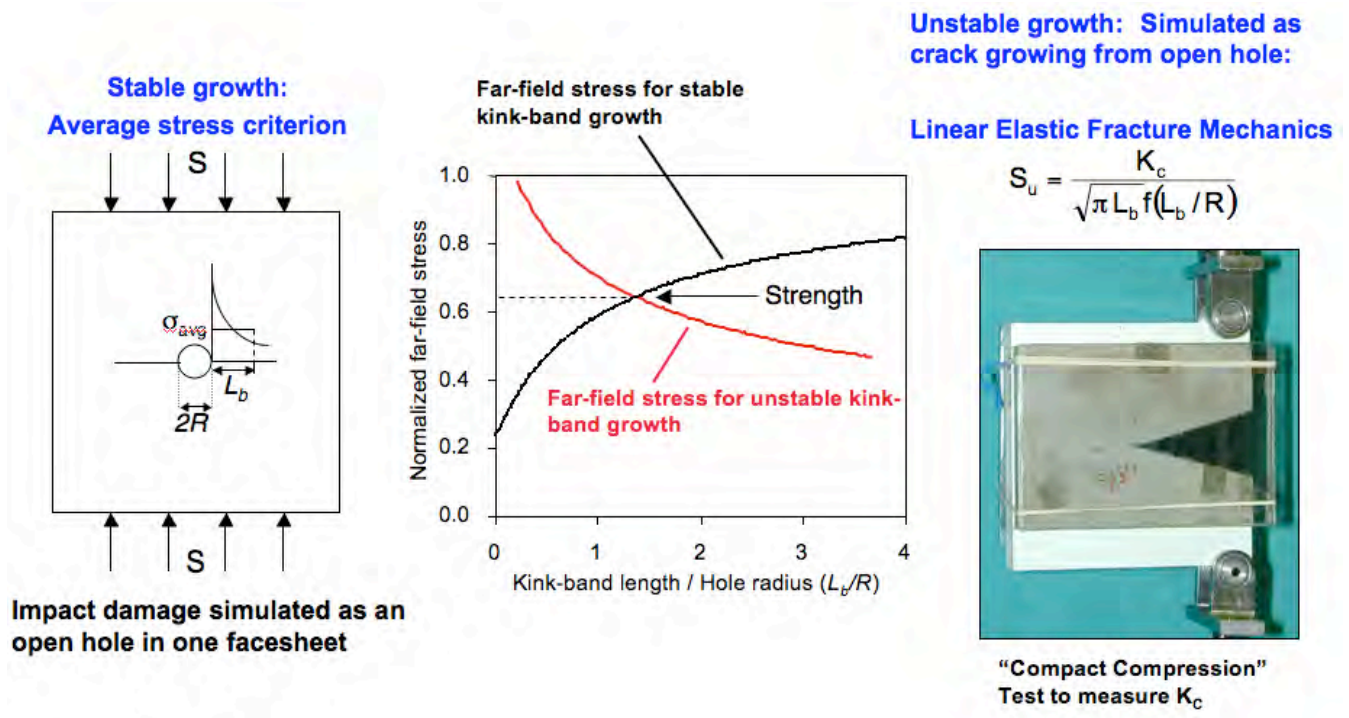

Figure 25: Computing residual compressive strength associated with kink-band-growth failure mode

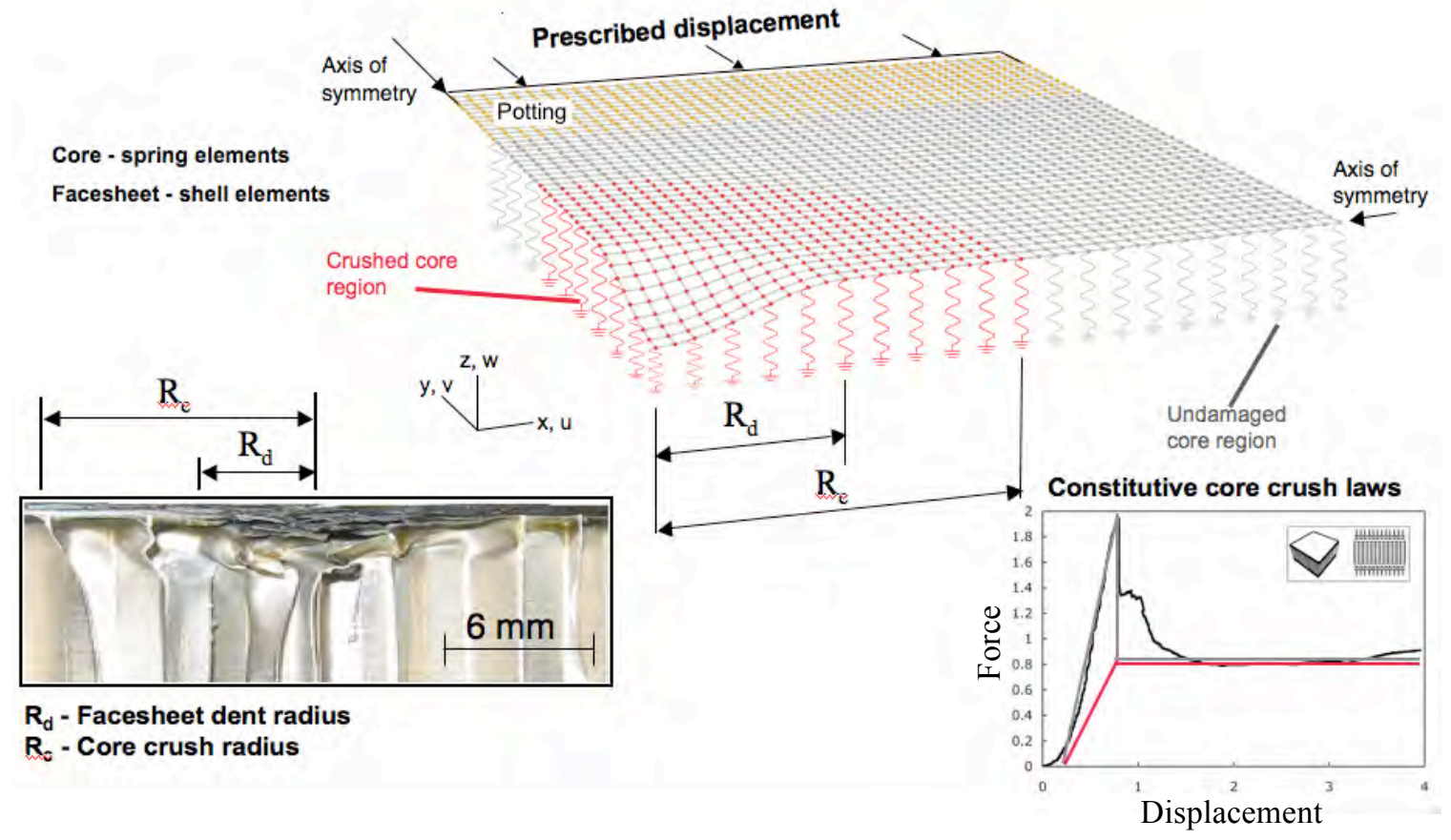

Figure 26: Finite element model for computing residual strength associated with indentation-growth 


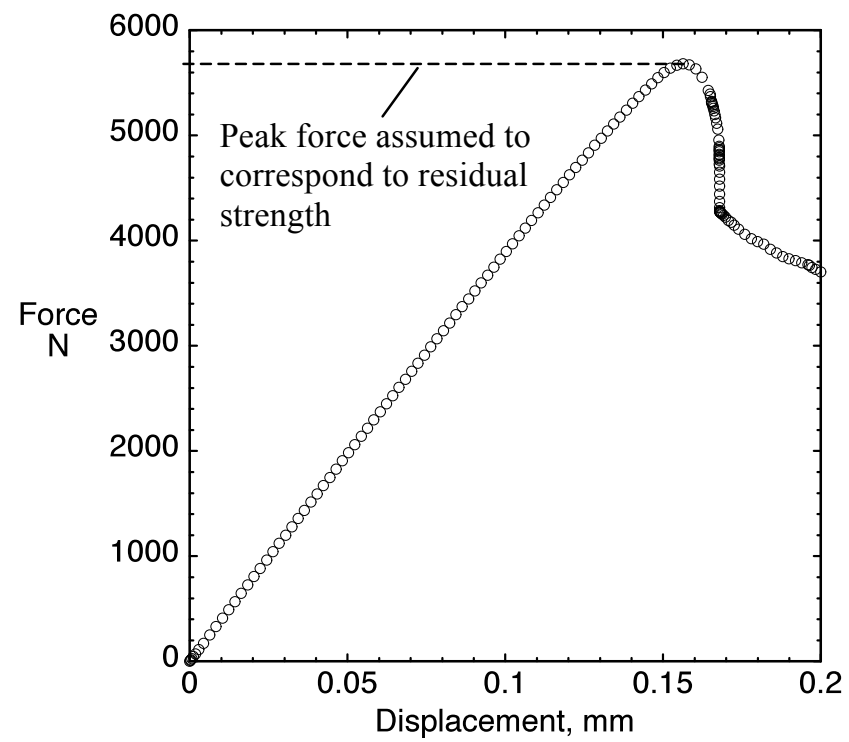

Figure 27: Computed sandwich panel force-displacement response

\section{Fractographic Analysis}

Expertise developed within the branch in the area of damage tolerance of composite laminates has lead to requests for participation in aviation accident investigations, as highlighted in the following discussion of a fractographic analysis conducted in the branch in support of the American Airlines 587 accident investigation.

The accident investigation concerned the American Airlines Airbus A300-600R aircraft that crashed shortly after takeoff from Kennedy International Airport in November, 2001. The National Transportation Safety Board (NTSB) determined that the likely cause of the crash was the in-flight separation of the vertical stabilizer, arising from loads beyond ultimate design that were applied to the stabilizer. It was found that the stabilizer had separated from the main fuselage of the aircraft via failures of the stabilizer's six main lug attachment points. Researchers from the branch were requested by the NTSB to conduct fractographic analysis on samples removed from the aircraft debris as part of an effort to determine the cause of the accident ${ }^{59}$.

Prior to the main fractography activities, a series of studies were conducted to evaluate the general configuration of the laminated structure, including stacking sequence, void content, chemical composition and glass transition temperature. Specimens were removed from recovered debris, edges polished and examined optically to determine stacking sequence and void content. Infrared spectroscopy (IR) was used to determine chemical composition and differential scanning calorimetry (DSC), amongst other methods, was used to determine glass transition temperature, $\mathrm{T}_{\mathrm{g}}$. These investigations indicated that the general state of the laminate was consistent with that prescribed by the manufacturers specifications. 
An initial optical microscopy investigation was performed on recovered debris in order to establish a preliminary determination of the sequence of events and failure mechanisms involved in the failure of the composite lugs during detachment of the vertical stabilizer. This investigation determined that the three right-hand lugs failed in tension due to the bending moment-induced overloading, followed by a combination of tensile and compressive failures of the three left-hand lugs, caused by the continued bending deformation of the stabilizer after the right-hand lugs had failed.

The remaining challenge for the investigation was to determine whether any fracture events, such as delamination fatigue, had occurred prior to the accident. To address this, an extensive examination of recovered debris was conducted using scanning electron microscopy (SEM), involving magnifications ranging from 250X to over 2000X. This series of inspections revealed that no fracture events occurred prior to the accident, supporting the hypothesis that the failure was associated with unanticipated, in-flight loading, rather than damage that may have accumulated during the service of the aircraft. Data from the inspections also revealed the fracture modes that took place in each lug, and the direction of fracture propagation. For instance, the micrograph shown in Figure 28 was used to reveal fracture surface features of broken fibers in a lug that had failed under tension ${ }^{59}$. In this instance, the crack growth direction of individual broken fibers (indicated by white arrows in Figure 28) was averaged to determine an overall direction of fracture in this section of the lug ${ }^{59}$.

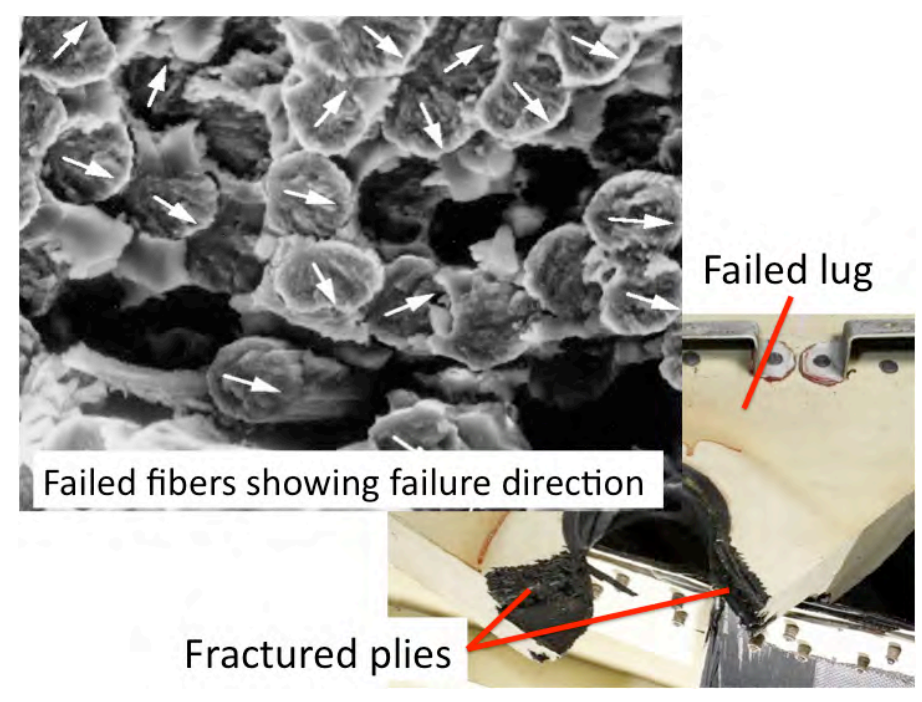

Figure 28: Micrograph of failed fibers in lug attachment

\section{Summary}

An overview of computational, analytical and experimental strategies for fracture mechanics and its application to understanding damage tolerance of aerospace structures made of metallic and composite materials has been presented. Methodologies for simulating and characterizing damage growth in metallic materials under monotonic and 
cyclic loading were presented, including continuum-based mechanics as well a new paradigm in damage mechanics, damage science. In addition, damage tolerance capabilities for composite materials including current computational and experimental methods for composite structures were discussed.

A multiscale view of fracture mechanics for metallic materials is being developed with the aim of better understanding the fundamental mechanisms of damage progression at each relevant length scale. At the continuum scale, methods for predicting residual strength and fatigue crack growth in friction stir welded aluminum panels were presented. New investigations into the mechanisms of fatigue crack closure demonstrated that remote closure can occur when the testing parameters recommended by the testing standard, ASTM E647, are greatly exceeded. These continuum-level behaviors in metallic materials have underpinnings at the micro- and nano-scales, so an understanding of the myriad of microscale and nanoscale mechanisms is needed to fully understand continuum fracture mechanics. Thus, Damage Science methodologies are being developed to facilitate the understanding of durability and damage tolerance at a very fundamental level.

Recent developments for composite materials include the development of standardized test methods for delamination growth, prediction and verification methods for characterization of delamination and debonding, and fractographic analysis for determining underlying mechanisms of damage. The development of standardized test methods for composite materials is focused on developing a means for generating reliable data for characterizing delamination growth rate under constant amplitude fatigue loading. In addition, a test method for characterizing facesheet-core peel debonding in sandwich structure is being developed based on a specimen sizing method acceptable for use in a standardized test protocol. Other developments for composite materials include, methods for predicting delamination growth in z-pin-reinforced laminates, determining the effect of the z-pins on laminate compressive strength, and predicting the residual compressive strength of impact-damaged sandwich panels. Finally, fractographic analysis has been used to determine mechanisms of delamination growth and laminate failure during the American Airlines Flight 587 accident investigation.

\section{Acknowledgements}

The authors would like to thank the members of the Durability, Damage Tolerance, and Reliability Branch for their contributions to this paper. In particular, the authors are grateful to Dr. Ronald Kruger for his thorough review of this paper.

\section{References}

1. Smith, S.W., Newman, J.A., James, M.A., Donald, J.K., Brazill, R.L., Schultz, R.W., Blair, A. and Seshadri, B.R., "An On-line Methodology for Measuring Residual Stress and Producing Reliable Fatigue Life Assessments," ASTM Journal of Testing and Evaluation, to be submitted. 
2. ASTM International Standard E647-08 "Standard Test Method for Measurement of Fatigue Crack Growth Rates" 2008 ASTM International Annual Book of Standards, Vol. 03.01, ASTM International, West Conshohocken, PA.

3. Newman, Jr. J.C. and Yamada, Y., "Compression Precracking Methods to Generate Near-threshold Fatigue-crack Growth-rate Data," International Journal of Fatigue, in press as of August 2009.

4. Forth, S.C., Newman, Jr. J.C. and Forman, R.G., "On Generating Fatigue Crack Growth Thresholds," International Journal of Fatigue, Vol. 25, 2003, pp. 9-15.

5. Elber, W., "Fatigue Crack Closure Under Cyclic Tension," Engineering Fracture Mechanics, Volume 2, 1970, pp. 37-45.

6. Newman, J.A. and Piascik, R.S., "Plasticity and Roughness Closure Interactions Near the Fatigue Crack Growth Threshold," Fatigue and Fracture Mechanics: 33rd Volume, ASTM STP 1417,W. G. Reuter and R. S. Piascik, Eds., ASTM International, West Conshohocken, PA, 2002.

7. Suresh, S., Fatigue of Materials, Cambridge University Press, 1991, Cambridge, UK.

8. Newman, J.A., The Effects of Load Ratio on Threshold Fatigue Crack Growth of Aluminum Alloys, Ph.D. dissertation, 2000, Virginia Polytechnic Institute and State University.

9. Piascik, R.S., Newman, Jr. J.C, and Underwood, J.H., "The Extended Compact Tension Specimen," Fatigue and Fracture of Engineering Materials and Structures, Vol. 20, 1997, pp. 559-563.

10. Fracture Technology Associates, User's Reference Manual for Automated Fatigue Crack Growth (Compliance), Version 2.43, Fracture Technology Associates, Bethlehem, PA.

11. Deans, W.F., Jolly, C.B., Poyton, W.A. and W. Watson, "A Strain Gauging Technique for Monitoring Fracture Specimens During Environmental Testing," Strain, Vol. 13, 1977, pp. 152-154.

12. Sutton, M.A., Orteu, J.-J. and Schreier, H.W., "Image Correlation for Shape, Motion and Deformation Measurements," Springer Science Business Media, New York, NY, 2009.

13. Elber, W., "Crack Closure and Crack Growth Measurements in Surface-Flawed Titanium Alloy Ti-6Al-4V," 1975, NASA TN-D-8010.

14. Leser, W.P., Newman, J.A. and Smith, S.W., "Fatigue Crack Closure Analysis Using Digital Imaging," To be submitted.

15. Riddell, W.T. and Piascik, R.S., "Stress Ratio Effects on Crack Opening Loads and Crack Growth Rates in Aluminum Alloy 2024," NASA/TM-1998-206929.

16. Hutchinson, J.W., "Plasticity at the Micron Scale," International Journal of Solids and Structures, vol. 37, 2000, pp. 225-238.

17. Hochhalter, J.D., Littlewood, D.J., Christ, R.J., Veilleux, M.G., Bozek, J.E., Ingraffea, A. and Maniatty, A.M., "A Geometric Approach to Modeling Microstructurally Small Fatigue Crack Formation: II. Physically-based Modeling of Microstructure-dependent Slip Localization and Actuation of the Crack Nucleation Mechanism in AA 7075-T651," Modelling and Simulation in Materials Science and Engineering, Vol. 18, 2010. 
18. Bozek, J.E., Hochhalter, J.D., Veilleux, M.G., Liu, M., Heber, G., Sintay, S.D., Rollett, A.D., Littlewood, D.J., Maniatty, A.M., Weiland, H., Christ Jr., R.J., Payne, J., Welsh, G., Harlow, D.G., Wawrzynek, P.A. and Ingraffea, A.R., "A Geometric Approach to Modeling Microstructurally Small Fatigue Crack Formation: I. Probabilistic Simulation of Constituent Particle Cracking in AA 7075-T651," Modelling and Simulation in Materials Science and Engineering, vol. 16, 2008.

19. Sun, S., Adams, B.L. and King, W.E., "Observations of Lattice Curvature Near the Interface of a Deformed Aluminum Crystal," Philosophical Magazine A, Vol. 80, No. 1, 2000, pp. 9-25.

20. Kysar, J.W. and Briant, C.L., "Crack Tip Deformation Fields in Ductile Single Crystals," Acta Materialia, Vol. 50, 2002, pp. 2367-2380.

21. Nye, J.F., "Some Geometrical Relations in Dislocated Crystals," Acta Metallurgica, Vol. 1, 1953, pp. 153-162.

22. Gupta, V.K., Ph.D. Dissertation, University of Virginia, Charlottesville, 2009.

23. Arsenlis, A., Cai, W., Tang, M., Rhee, M., Oppelstrup, T., Hommes, G., Pierce, T.G., and Buylatov, V.V., "Enabling Strain Hardening Simulations with Dislocation Dynamics," Modelling and Simulation in Materials Science and Engineering, Vol. 15, 2007, pp. 553-595.

24. Glaessgen, E.H., Saether, E., Hochhalter, J.D. and Yamakov, V., "Modeling NearCrack-Tip Plasticity at Nano to Micro Scales," To be presented at the 51st AIAA/ASME/ASCE/AHS/ASC Structures, Structural Dynamics and Materials Conference and Exhibit, Orlando, FL, April 12-15, 2010.

25. Allen MP, Tildesley DJ. "Computer Simulation of Liquids," Oxford science publications: Oxford, 1987.

26. Saether, E., Yamakov, V., Glaessgen, E.H., "An Embedded Statistical Method for Coupling Molecular Dynamics and Finite Element Analyses," International Journal of Numerical Methods and Engineering, Vol. 78, 2009, pp. 1292-1319.

27. Yamakov, V., Saether, E., Phillips, D. R., Glaessgen, E. H., "Molecular-Dynamics Simulation-Based Cohesive Zone Representation of Intergranular Fracture Processes in Aluminum," Journal of the Mechanics and Physics of Solids, Vol. 54, 2006, pp. 1899-1928.

28. Farkas, D., Duranduru, M., Curtin, W. A., Ribbens, C, "Multiple-Dislocation Emission from the Crack Tip in the Ductile Fracture of Al," Philosophical Magazine $A$, Vol. 81, 2001, pp. 1241-1255.

29. Hai, S., Tadmor, E. B., "Deformation Twinning at Aluminum Crack Tips," Acta Materialia, Vol. 51, 2003, pp. 117-131.

30. Tadmor, E. B., Hai, S., "A Peierls Criterion for the Onset of Deformation Twinning at a Crack Tip," Journal of the Mechanics and Physics of Solids, Vol. 51, 2003, pp. 765793.

31. Warner, D. H., Curtin, W. A., Qu, S., "Rate dependence of Crack-Tip Processes Predicts Twinning Trends in f.c.c. Metals," Nature Materials, Vol. 6, 2007, pp. 876880.

32. Yamakov, V., Saether, E., and Glaessgen, E., "A Continuum-Atomistic Analysis of Transgranular Crack Propagation in Aluminum", $50^{\text {th }}$ AIAA/ASME/ASCE/AHS/ASC Structures, Structural Dynamics and Materials Conference and Exhibit, Palm Springs, CA, May 4-7, 2009.

33. ASTM International Standard D5528-01 (2007), "Standard Test Method for Mode I Interlaminar Fracture Toughness of Unidirectional Fiber-Reinforced Polymer Matrix Composites," 2008 ASTM International Annual Book of Standards, Vol. 15.03, ASTM International, West Conshohocken, PA.

34. ASTM International Standard D6415/D 6415M-06a, "Standard Test Method for Measuring the Curved Beam Strength of Fiber-Reinforced Polymer-Matrix Composites," 2008 ASTM International Annual Book of Standards, Vol. 15.03, ASTM International, West Conshohocken, PA. 
35. Paris, I., "Mode I Fatigue Delamination Propagation of Unidirectional FiberReinforced Polymer Matrix Composites (DCB)," ASTM International Committee D30 Inter-laboratory Study, ILS \# 0189, 2009.

36. ASTM International Standard D6115-97 (2004), "Standard Test Method for Mode I Fatigue Delamination Growth Onset of Unidirectional Fiber-Reinforced Polymer Matric Composites," 2008 ASTM International Annual Book of Standards, Vol. 15.03, ASTM International, West Conshohocken, PA.

37. Rybicki, E.F. and Kanninen, M.F., "A Finite Element Calculation of Stress Intensity Factors by a Modified Crack Closure Integral," Engineering Fracture Mechanics, vol. 9, pp. 931-938, 1977.

38. Krueger, R., "An Approach to Assess Delamination Propagation Simulation Capabilities in Commercial Finite Element Codes," NASA/TM-2008-215123, 2008.

39. Poe, Jr., C.C. and Harris, C.E., "Mechanics of Textile Composites Conference," NASA Contractor Report, NASA/CP-3311, Parts 1 and 2, 1995.

40. Freitas, G., Magee, C., Boyce, J. and Bott, R., "Service Tough Composite Structures using the Z-Direction Reinforcement Process", Proceedings of the 9th DoD/NASA/FAA Conference on Fibrous Composites in Structural Design, Lake Tahoe, Nevada, USA, November 1991, NASA-CR-198718.

41. Ratcliffe, J. and O'Brien, T.K., "Discrete Spring Model for Predicting Delamination Growth in Z-Fiber Reinforced DCB Specimens," NASA Technical Memorandum, NASA/TM-2004-213019, 2004.

42. Cartié, D.D.R., and Partridge, I.K., "A Finite Element Tool For Parametric Studies of Delamination In Z-Pinned Laminates," Proceedings of the Sixth International Conference on Deformation and Fracture of Composites, Manchester, UK, April 2001, pp.49-55.

43. Robinson, P., and Das, S., "Mode I DCB Testing of Z-Fiber Reinforced Laminates: A Simple Model for the Investigation of Data Reduction Strategies," Journal of Engineering Fracture Mechanics, Vol. 71, No. 3, 2004, pp. 345-364.

44. Steeves, C.A., Mechanics of Failure in Composite Structures, Ph.D. Dissertation, Department of Engineering, University of Cambridge: Cambridge, United Kingdom, 2001.

45. Sun, C.T., "Novel Methods for Testing and Modelling Composite materials and Laminates," Proceedings of the Second International Conference on Composites Testing and Model Identification, CompTest 2004, Bristol, England, September, 2004.

46. Sun, C.T. and Jun, A.W., Compressive Strength of Unidirectional Composites with Matrix Non-linearity," Composites Science and Technology, Vol. 52, No. 4, pp. 577587.

47. Fleck, N.A. and Shu, J.Y., Microbuckle Initiation in Fibre Composites: A Finite Element Study, Journal of Mechanics and Physics of Solids, Vol.43, No.2, 1995, pp.1887-1918.

48. Shu, J.Y. and Fleck, N.A., User's Manual for Finite Element Code for Fibre Microbuckling, Cambridge University Engineering Department C-MATS Technical Report 224 (ISSN 0309-6505), May, 1995.

49. Liu, D. and Fleck, N.A., "User's manual II for Finite Element Code FLASH for Fibre Microbuckling," Cambridge University Engineering Department C-MICROMECH Technical Report 29 (ISSN 0309-7420), November, 1999.

50. T. K. O'Brien and R. Krueger, "Influence of Compression and Shear on the Strength of Composite Laminates with Z-Pinned Reinforcement," Applied Composite Materials, Vol. 13, pp. 173-189, 2006.

51. Budiansky, B. and Fleck, N.A., Compressive Failure of Fibre Composites, Journal of Mechanics and Physics of Solids, Vol. 41, No. 1, 1993, pp.183-211.

52. Weaver, C., "Evaluation of Mode I Fracture Mechanics Test Methods for Sandwich Composites," M.Sc Thesis, University of Utah, Salt Lake City, UT, 2009. 
53. Ratcliffe, J, "Sizing Single Cantilever Beam Specimens for Characterizing Facesheet/Core Peel Debonding in Sandwich Structure," NASA Technical Publication, NASA/TP-2010-216169, 2010.

54. Li, X., and Carlsson, L.A., "Elastic Foundation Analysis of Tilted Sandwich Debond (TSD) Specimen," Journal of Sandwich Structures and Materials, Vol. 2, 2000, pp. 3-32.

55. Cvitkovich, M.K., and Jackson, W.C., "Compressive Failure Mechanisms in Composite Sandwich Structures," Journal of the American Helicopter Society, Vol. 44 (4), pp. 260-268, 1999.

56. Ratcliffe J., Jackson, W.C., and Schaff, J., "Compression Strength Prediction of Impact-Damaged Composite Sandwich Panels," Proceedings of the American Helicopter Society 60th Annual Forum, Baltimore, MD, June 7-10, 2004.

57. Soutis, C., and Fleck, N.A., "Static Compression Failure of Carbon Fibre T800/924C Composite Plate with a Single Hole," Journal of Composite Materials, Vol. 24, pp. 536-558, 1990.

58. Ratcliffe, J., and Jackson, W.C., "A Finite Element Analysis for Predicting the Residual Compressive Strength of Impact-Damaged Sandwich Panels," NASA Technical Memorandum, NASA/TM-2008-215341, 2008.

59. Fox, R.F., Schulteisz, C.R., Reeder, J.R. and Jensen, B.J., "Materials Examination of the Vertical Stabilizer from American Airlines Flight 587," Proceedings of Materials Science and Technology, Vol. 2, pp. 171-185, 2005, 